\title{
Polymer/montmorillonite nanocomposites with improved thermal properties.
}

\section{Part I: Factors influencing thermal stability and mechanisms of thermal stability improvement}

\author{
A. Leszczyńskaa ${ }^{a}$ J. Njuguna ${ }^{b}$, K. Pielichowski ${ }^{a, "}$, J. R. Banerjee \\ ${ }^{a}$ Department of Chemistry and Technology of Polymers, Cracow University of Technology, \\ ul. Warszawska 24, 31-155 Kraków, Poland. \\ ${ }^{\mathrm{b}}$ School of Industrial and Manufacturing Science, Cranfield University, \\ Cranfield, Bedfordshire, MK43 0AL, UK. \\ ${ }^{\mathrm{c}}$ School of Engineering and Mathematical Sciences, City University, \\ Northampton Square, London, EC1V 0HB, UK.
}

\begin{abstract}
The results of recent research indicate that the introduction of layered silicate montmorillonite - into polymer matrix results in increase of thermal stability of a number of polymer nanocomposites. Due to characteristic structure of layers in polymer matrix and nanoscopic dimensions of filler particles, several effects have been observed that can explain the changes in thermal properties. The level of surface activity may be directly influenced by the mechanical interfacial adhesion or thermal stability of organic compound used to modify montmorillonite. Thus, increasing the thermal stability of montmorillonite and resultant nanocomposites is one of the key points in the successful technical application of polymer/clay nanocomposites on the industrial scale. Basing on most recent research, this work presents a detailed examination of factors influencing thermal stability, including the role of chemical constitution of organic modifier, composition and structure of nanocomposites, and mechanisms of improvement of thermal stability in polymer/montmorillonite nanocomposites.
\end{abstract}

\footnotetext{
* Corresponding author: Tel.+ 4812 6282727, Fax: +48 12 6282038, e-mail: kpielich@usk.pk.edu.pl (K. Pielichowski).
} 
Keywords: Polymer nanocomposites, montmorillonite, thermal stability, degradation. 


\section{Introduction}

Although the organo-clay complexes have been recognized for a long time $[1,2]$ the interest in studying these layered silicate materials as nanoscale-reinforcing agents for polymeric materials has only been developed recently. The introduction of as low as 1-5 wt. $\%$ of montmorillonite (MMT) into polymer matrix is well-known to result in significant improvement in mechanical strength due to nanometric dimensions and high aspect ratio. The nanoscopic phase distribution as well as synergism between polymer and the layered silicate result in additional properties, such as flame retardation, enhanced barrier properties and ablation resistance, which are not observed in either component [3-6]. The layered silicates used for this purpose are mica, fluoromica, hectorite, fluorohectorite, saponite, etc., but of the greatest commercial interest is montmorillonite (MMT) that belongs to the structural family known as the 2:1 phyllosilicates. Their crystal structure consists of layers made up of two silica tetrahedral sheets fused to an edge-shared octahedral sheet of either aluminium or magnesium hydroxide. Stacking of the layers leads to a regular van der Waals gap between the layers (the interlayer or gallery). Isomorphic substitution within the layers generates charge deficiency (i.e. $\mathrm{Fe}^{2+}$ or $\mathrm{Mg}^{2+}$ replacing $\mathrm{Al}^{3+}$ in $\mathrm{MMT}$ and $\mathrm{Li}^{+}$replacing $\mathrm{Mg}^{2+}$ in hectorite). The deficit charges are compensated by cations (usually $\mathrm{Na}^{+}$or $\mathrm{K}^{+}$) absorbed between the three-layer clay mineral sandwiches. These are held relatively loosely and give rise to the significant cation-exchange properties.

Polymer-layered silicate nanocomposites are currently prepared in four ways - in situ polymerisation, intercalation from a polymer solution, direct intercalation by molten polymer and sol-gel technology [7]. Direct polymer melt intercalation is the most attractive because of its low cost, high productivity and compatibility with current polymer processing techniques. Polymer/clay nanocomposites preparation involves high temperatures irrespective of the fabrication route. If the processing temperature is higher than the thermal stability of the organic component used for montmorillonite modification, decomposition will take place, leading to variations between the filler and polymer. Thus, determination of the onset temperature of degradation, resultant products of degradation and the stability of the polymer in the presence of layered silicates as well as understanding the relationship between the molecular structure and the thermal stability (decomposition temperature, rate, and the degradation products) of the organic modification of the layered silicate is critical $[8,9]$. In particular, thermal stability was considered as an important factor playing role in the 
nanocomposite structure and morphology formation [10]. Studies have shown that different methods of synthesis and types of organophilic MMT influence the morphology and thermal stability of polymer/clay nanocomposites. For instance, studies on polyamide 11/clay nanocomposites have reported that the enhanced thermal stability is only achieved at quite low loading level, thus making the obtained nanocomposites cheaper, lighter and easier to process than the conventional microcomposites; the improvement in thermal stability is much more significant for the exfoliated nanocomposites than that for the intercalated ones [11].

\section{Parameters influencing the thermal stability of polymer/MMT nanocomposites}

\subsection{The role of organic modifier on thermal stability of polymer/MMT nanocomposites}

For the majority of polymers, owing to their hydrophobic character, the clay must be modified with a surfactant in order to make the gallery space sufficiently hydrophobic to permit it to interact with the polymer.

\section{Ammonium compounds}

The surfactant is usually described as an 'onium' salt, but in fact ammonium salts are most commonly used. The commonly used organo-modification agents are long carbon-chain alkyl ammonium salts. The quaternary ammonium ion is nominally chosen to compatibilize the layered silicate with a given polymer resin. However, the molecular structure, such as alkyl chain length, number of alkyl chains and unsaturations, is also the determining factor of the thermal stability of the polymer/MMT nanocomposites [12]. Although these modification agents have been gaining significant success in the preparation of polymer/MMT nanocomposites, their common shortcoming is the poor thermal stability. The thermal stability of the organoclay component is of major importance, as many polymer composites are either melt-blended or intercalated at high temperatures to yield distribution of filler in the nanoscale. All the nanocomposite components may be subjected to high temperatures during preparation process, further processing and service time. If the processing temperature is higher than the thermal stability of the organoclay, then decomposition occurs, and the interface between the filler and the matrix polymer is effectively altered. There has been done a substantial work on studying the degradation process of organoclays and nanocomposites as well as significant successes were noted in the elaborating of thermally stable organic 
modifiers for compatibilizing the clay and polymer matrix, but still some questions remain unanswered.

The degradation process of intercalated montmorillonite reveals significant differences. For instance, pure montmorillonite do not exhibit any significant mass loss due to decomposition processes in a temperature up to $300^{\circ} \mathrm{C}$. Early investigations by Greene-Kelly [13] considered the MMT differential thermal curve in two parts: the free water and interlayer water region in the temperature range $100-300^{\circ} \mathrm{C}$ and the structural water (bonded hydroxyl groups that undergo dehydroxylation) region in the temperature range $500-1000^{\circ} \mathrm{C}$. Studies by Xie et al. [12,14] reported the thermal stability of MMT modified by long carbon-chain alkyl quaternary ammonium ions and found that the onset decomposition temperature of the resultant organically modified layered silicates (OLS) was approximately $180^{\circ} \mathrm{C}$. Interestingly, investigations by Zheng and Wilkie [15] reported that methyl tallow bis-2hydroxyethyl ammonium modified clay and dimethyl dihydrogenated tallow alkyl ammonium modified clay showed very good thermal stability, with $10 \%$ degradation (10\% mass loss) occurring around $390^{\circ} \mathrm{C}$. Investigations by Xie et al. [14] reported that the thermal decomposition of organic substances between silicate layers was mainly in the range 200$500^{\circ} \mathrm{C}$. A follow-up work showed that the $\mathrm{Na}^{+}-\mathrm{MMT}$ exhibited no weight loss in this range of temperature; in contrast, the organic MMTs (modified with dimethyldioctadecyl ammonium or trimethyloctadecyl ammonium) exhibited significant weight loss [16]. The MMT modified with dimethyldioctadecyl ammonium exhibited larger weight loss in the range of $200-350^{\circ} \mathrm{C}$ than MMT modified by trimethyloctadecyl ammonium. This indicated that the former contained more organic matter than the latter, which accounted for the larger interlayer distance of MMT modified with dimethyldioctadecyl ammonium.

Hwu and co-workers [17] found OLS to decompose in two step process as shown in Fig.1.

Fig. 1

The first step of degradation proceeding with a maximum rate at about $200^{\circ} \mathrm{C}$ gave mainly long carbon chains with chloro or amine groups whereas the evolved gases during the second stage of degradation were composed mainly of both short and long carbon alkene chains without the chloro groups, as detected by GC/TOF-MS method. It was stressed that the gases evolved during OLS degradation at 200 and $220^{\circ} \mathrm{C}$ were the same as that of pure stearyltrimethyl ammonium chloride. However, the species detected at 300 and $400^{\circ} \mathrm{C}$ were 
different from that of pure organic compound. In nanocomposite material that seemed to have a mixed intercalated/exfoliated structure authors indicated two possible areas, the outside spaces of the silicate layers and the interlayer spaces, where decomposition of organic treatment could take place at different temperatures (Fig. 1). They explained that the first bond breakage in the organic compound might occur outside the clay sheets, between $\mathrm{N}$ and $\mathrm{C}$ bonds, at around $200^{\circ} \mathrm{C}$. Because there was less hindrance in the clay sheets, the formed compounds could evolve quickly without further degradation. The intercalated organic compounds decomposed at higher temperatures, and the decomposition reactions were more complete than that of outside organic compounds. Because of the hindrance in the clay sheets and the force between them, they evolved slowly and further decomposition occurred mainly between $\mathrm{C}$ and $\mathrm{C}$ bonds. From GC/TOF-MS results, comparing the trapped evolved gases at different temperatures for OLS, it was indicated that below $160^{\circ} \mathrm{C}$ the small amount of water, solvent $\left(\mathrm{C}_{3} \mathrm{H}_{8} \mathrm{O}\right)$, 1-chlorohexadecane and $N, N$-dimethyl-1-tridecanamine were evaporated. The detected water at $110^{\circ} \mathrm{C}$ was ascribed to the absorbed water. At higher temperatures, the water probably came from the reaction of the hydroxyl group in the clay sheets and organic compounds. Finally, no water or solvent was observed, but there were still similar species such as 1-chloro-hexadecane and $N, N$-dimethyl-1-tridecanamine determined even at decomposition temperature. This showed that the clay modified with stearyltrimethyl ammonium chloride was not stable even at lower temperatures.

Elsewhere, the OLS were demonstrated to have a different behaviour than $\mathrm{Na}^{+}-\mathrm{MMT}$. For instance, the free water $(\sim 1 \mathrm{wt} . \%)$ disappeared by $40^{\circ} \mathrm{C}[12]$. There was no interlayer water in the OLS as the quaternary ammonium salt had been exchanged for the hydrated sodium cation. The free and interlayer water (total $\sim 4$ wt. \%) started evolving about $90^{\circ} \mathrm{C}$ for pristine $\mathrm{Na}^{+}-\mathrm{MMT}$, but were not completely gone until about $300^{\circ} \mathrm{C}$. In the temperature range $500-800^{\circ} \mathrm{C}$, the hydroxyl groups, which covalently incorporated in the crystal lattice, were dehydrated. It has been proposed that the organic modifiers start decomposing at temperature around $200^{\circ} \mathrm{C}$, and the small molecular weight organics are released first while the high molecular weight organic species are still trapped by OLS matrix $[13,18,19]$. With the increase of temperature, the high molecular organic compunds not only decomposed, but were also released from OLS. This phenomenon was also observed by Xie et al. [12] using differential thermal analysis (DTA) and MS, and led to proposition that the organic compounds with a small molecular weight may be released first and those with a relatively high molecular weight may still exist between the interlayers until the temperature is high enough to lead to their further decomposition. X-ray measurements found out that by over 
$300^{\circ} \mathrm{C}$ the (001) spacing decreased from about $15 \AA$ for Ca-saturated or 11-12.5 $\AA$ for $\mathrm{Na}$ saturated samples to $9.5 \AA$ and that no further decrease occurred at higher temperature $[18,19]$. It was concluded, therefore, that in this temperature range the bulk of the water is lost from the interlayer space.

The thermal degradation of ammonium salts generally proceeds either by a Hofmann elimination to give a product different from the amine, or an $\mathrm{S}_{\mathrm{N}} 2$ nucleophilic substitution reaction to produce the amine. During thermal degradation proceeding according to the Hofmann degradation mechanism the ammonium cation loses an olefin and an amine and leaves an acid proton on the surface of the MMT [14]. This acid site on the surface of MMT probably has a catalytic effect during the initial stages of decomposition of organic material within the OLS.

The studies on the effect of alkyl chain length and saturation on the thermal stability of the OLS found the decomposition product was a mixture of alkanes and alkenes [12]. Additionally, $\mathrm{NH}_{3}$ was proposed possible but was difficult for the study to confirm since the characteristic MS peak of $\mathrm{NH}_{3}$ was overlapping with that of water. However, the IR spectra showed emission of $\mathrm{NH}_{3}$ product because of the presence of following reversible reactions:

$$
\begin{aligned}
& \mathrm{M}-\mathrm{R}_{3} \mathrm{NH}^{\oplus}+\mathrm{H}_{3} \mathrm{O}^{\oplus} \rightleftharpoons \mathrm{M}-\mathrm{R}_{2} \mathrm{NH}_{2}{ }^{\oplus}+\mathrm{RH}_{2} \mathrm{O}^{\oplus} \\
& \mathrm{M}-\mathrm{R}_{2} \mathrm{NH}_{2}^{\oplus}+\mathrm{H}_{3} \mathrm{O}^{\oplus} \rightleftharpoons \mathrm{M}-\mathrm{RNH}_{3}^{\oplus}+\mathrm{RH}_{2} \mathrm{O}^{\oplus} \\
& \mathrm{M}-\mathrm{RNH}_{3}{ }^{\oplus}+\mathrm{H}_{3} \mathrm{O}^{\oplus} \rightleftharpoons \mathrm{M}-\mathrm{NH}_{4}{ }^{\oplus}+\mathrm{RH}_{2} \mathrm{O}^{\oplus}
\end{aligned}
$$

Since the only difference among the samples prepared was that the organically modified MMT contained quaternary ammonium cations with three methyl substituents and one long alkyl substituent (coco, tallow, dodecyl and octadecyl) was the fourth substituent, their thermal behaviours could be determined by the susceptibility of long alkyl chain to undergo degradation reactions. The onset decomposition temperature $\left(\mathrm{T}_{\text {onset }}\right)$ was considered an index for the thermal stability of OLS. Based on the $\mathrm{T}_{\text {onset, }}$ it was concluded that different ammonium compounds had no or very little effect on their thermal decomposition in the presence of clay [12]. The DTG curves for the nanocomposites in Xie et al. work were considered in four parts: the free water region in the temperature below $200^{\circ} \mathrm{C}$; the region where organic substances evolve in the temperature range $200-500^{\circ} \mathrm{C}$; the structural water region in the temperature range $500-800^{\circ} \mathrm{C}$; and a temperature region between 800 and $1000^{\circ} \mathrm{C}$, where organic carbon reacts in some yet unknown way. It was observed that one of the most distinguishing differences between sodium MMT $\left(\mathrm{Na}^{+}-\mathrm{MMT}\right)$ and the organically 
modified MMT (OMMT) was in the temperature range of $800-1000^{\circ} \mathrm{C} . \mathrm{Na}^{+}-\mathrm{MMT}$ is very stable when the temperature is higher than $800^{\circ} \mathrm{C}$, however, according to the experimental results, the OMMT continued to lose weight with large amounts of $\mathrm{CO}_{2}$ being released at temperature over $800^{\circ} \mathrm{C}$. The explanation given was that the onium ion decomposition products, including alkanes and alkenes, were partially absorbed on the surface of the aluminosilicate. Subsequently, the absorbed organic structures were catalysed by the aluminosilicate to $\mathrm{CO}_{2}$ and/or the high temperature reaction of the carbon in the organic moiety with the oxygen in the crystal structure of the MMT took place.

Osman et al. have investigated the structure of alkylammonium molecules with different number and chain length of alkyl substituents self-assembled on MMT platelets. Depending on the cross-sectional area, the available area/cation, and the alkyl chain length, the molecules adopted a two-dimensional order or a disordered state at ambient temperatures. At a certain length and number of chains, the molecules adopted an ordered state due to increasing chain interactions and packing density. In the ordered state, the alkyl chains preferentially arrange in trans conformation. With increasing temperature, conformational transformation of the chains takes place, leading to a dynamically disordered phase (liquid-like). Although the translational freedom of the chains is restricted by the electrostatic binding of the headgroups to the substrate, the conformational transformation leads to chains with random conformation and destroys the two-dimensional order [20].

Further analysis of the ultra thin alkylammonium film covering the mineral surface revealed a correlation between the extent of cation exchange, arrangement of alkylammonium molecules and thermal stability of organically modified silicates. Authors have found that in the final stage of the exchange, some alkylammonium molecules are intercalated between the ionically bonded ones in a tail-to-tail arrangement leading to a local bilayer. This local bilayer as well as the non-reacted ammonium salt molecules decompose at lower temperatures than the self-assembled monolayer (SAM) and decrease the thermal stability of the OLS. The thermal stability of the organic monolayer depended on its chemical structure and purity as well as on the nature of the substrate. In general, dialkylammonium SAM were more stable than the monoalkyl derivatives. Neither the decomposition onset temperature nor the temperature of maximum mass loss rate was useful as an index for the stability of alkylammonium SAMs. The time needed for an isothermal mass-loss equal to $5 \%$ of that occurring across the first decomposition step was used as an index to compare the stability of different monolayers [21]. 
Other group has synthesized thermally stable, rigid-rod aromatic amine modifiers (Fig. 2) and applied them to prepare polyimide/MMT nanocomposites by in situ polymerization and melt intercalation method as well as poly(vinyl chloride) nanocomposites by the melt intercalation method [22].

Fig. 2

However, in the case of PVC nanocomposites the onset thermal decomposition temperature was only slightly increased - from $293^{\circ} \mathrm{C}$ for PVC to $302^{\circ} \mathrm{C}$ when the MMT content was below $1 \mathrm{wt} . \%$ [23]. When the MMT content increased continuously, the thermal stability of the nanocomposites decreased slowly, and, when the MMT content was $5 \mathrm{wt}$. \%, the onset decomposition temperature was the same as for pure PVC. Thermal stability results on PPMA and PP-g-MA nanocomposites of OMLS where ammonium cation containing methyl, tallow and two hydroxyethyl groups $(\mathrm{MT} 2 \mathrm{EtOH})$ was used as a organic modifier confirmed the negative influence of the hydroxyethyl reactivity, which tended to increase the concentration of radicals, favouring chain scission reactions and creation of weak bonds [24].

Although the ammonium compounds are effective in increasing the gallery spacing of MMT and make the composition of polymer and inorganic filler more compatible, other chemical compounds, such as phosphonium, pyridinium and imidazolium were considered as organic intercalant for MMT due to their higher thermal stability in comparison to ammonium compounds [25]. Further, Utracki considered the use of branched alkyl chains instead of linear or aromatic substituents to enhance the thermal resistance of ammonium compounds $[26]$.

Liang et al. [27] reported study on the organo-modification of MMT using thermally stable aromatic amines that contained phenyl structure and imide moiety and, unlike aliphatic amines, had very rigid chemical structure. The MMT-N-(4-(4'-aminophenoxy))phenyl phthalimide and MMT-N-4-(4'-aminophenyl)phenyl phthalimide clearly showed higher decomposition temperature compared to MMT-hexadecylamine because of the higher thermal stability of N-(4-(4'-aminophenoxy))phenyl phthalimide and N-(4-(4'-aminophenyl))phenyl phthalimide. The former showed slightly lower thermal stability because of the relatively poor thermal stability of ether linkage.

In another development, diprotonated forms of polyoxypropylene diamines of the type $a, \omega-\left(\mathrm{NH}_{3} \mathrm{CHCH}_{3} \mathrm{CH}_{2}\left(\mathrm{OCH}_{2} \mathrm{CHCH}_{3}\right)_{x} \mathrm{NH}_{3}\right)^{2+}$ with $x=2.6,5.6$, and 33.1, have been intercalated into MMT and fluorohectorite clays and subsequently evaluated for the formation 
of glassy epoxy/clay nanocomposites [28]. The intercalated onium ions functioned concomitantly as a clay surface modifier, intragallery polymerization catalyst and curing agent. Depending on the chain length of the diamine, different orientations of the propylene oxide oligochains were adopted in the clay galleries, resulting in basal spacings from $\sim 14 \AA$ (lateral monolayer, $x=2.6$ ) to $\sim 45 \AA$ (folded structure, $x=33.1$ ). In comparison to claymonoamine intercalates, the use of diamine intercalates greatly reduced the plasticizing effect of the alkyl chains on the polymer matrix, resulting in higher glass transition temperature and improved mechanical properties, while at the same time reducing the cost and time needed for nanocomposite fabrication.

\section{Imidazolium compounds}

To circumvent the detrimental effect of the lower thermal stability of alkyl ammonium-treated MMT, several works have been dealing with preparation of alkylimidazolium molten salts-treated MMT clays via ion exchange of the $\mathrm{Na}^{+}$-MMT with imidazolium salts and compared them to the conventional quaternary alkyl ammonium MMT $[29,30]$.

Prior to discussion concerning the thermal stability of imidazolium-intercalated MMT, one should focus on the thermal decomposition process of imidazolium salts and the role of their chemical structure.

Ngo et al. [31] and Begg et al. [32] found out that imidazole is resistant to ring fission during thermal rearrangements of 1-alkyl- and 1-aryl-imidazoles at temperatures above $600^{\circ} \mathrm{C}$, thus indicating that the imidazolium cation was more thermally stable than the alkyl ammonium cation. Notably, earlier research indicated that the facility with which various groups are cleaved from quaternary salts involves $\mathrm{S}_{\mathrm{N}} 1$ or $\mathrm{S}_{\mathrm{N}} 2$ mechanisms $[33,34]$. The pyrolysis of the imidazolium quaternary salt proceeds most likely via $\mathrm{S}_{\mathrm{N}} 2$ process (Fig. 3).

Fig. 3

Awad et al. [29] studied also the infuence of the anion type on thermal stability of the imidazolium salts. The hexafluorophosphate, tetrafluoroborate and bis(trifluoromethylsulfonyl)imide salts showed more than $100^{\circ} \mathrm{C}$ increase in the onset decomposition temperature compared to the halide salts. The thermal stability increased in the order: $\mathrm{PF}_{6}>\mathrm{N}\left(\mathrm{SO}_{2} \mathrm{CF}_{3}\right)_{2}>\mathrm{BF}_{4}>\mathrm{Cl}, \mathrm{Br}$. Additionally, the imidazolium thermal stability was affected by the type of isomeric structure of the alkyl side group. This was evidenced by the 
observation that both 1-butyl-2,3-dimethyl-imidazolium tetrafluoroborate and hexafluorophosphate salts had higher onset decomposition temperature than 1,2-dimethyl-3isobutyl-imidazolium tetrafluoroborate and hexafluorophosphate salts, respectively. The degradation reaction presumably proceeds via $\mathrm{S}_{\mathrm{N}} 1$ reaction since the cleavage of the tertiary carbon atom is likely to occur - Fig. 4.

Fig. 4

Further, methyl substitution in the 2-position (i.e. between the two $\mathrm{N}$ atoms) has been reported to enhance the thermal stability [35]. This is evident from the increase in the onset decomposition temperature of both 1-butyl-2,3-dimethyl-imidazolium chloride and 1,2dimethyl-3-hexadecyl-imidazolium chloride compared to 1-butyl-3-methyl-imidazolium chloride and 1-hexadecyl-3-methyl-imidazolium chloride, respectively; this effect may be due to the high acidic character of the $\mathrm{C} 2$ proton.

The experimental results concerning the thermal stability of immidazolium intercalated MMT showed a great increase as compared to ammonium-modified MMT. Moreover, higher thermal stability was observed for dimethyl hexadecyl-imidazoliumintercalated MMT than the dimethyl hexadecyl - imidazolium chloride and bromide salts, which was explained as due to the removal of the halide effect. However, it was observed that there was no significant improvement in the thermal stability of the intercalated tetrafluoroborate and hexafluorophosphate compounds comparing to molten salts due to the weak nucleophilicity of $\mathrm{BF}_{4}{ }^{-}$and $\mathrm{PF}_{6}{ }^{-}$anions. The results also indicated that the thermooxidative stability of imidazolium-treated MMT decreased as the chain length of the alkyl group attached to the nitrogen atom increased. FTIR analysis of the decomposition products showed among decomposition products water, carbon dioxide and hydrocarbons [29].

\section{Phosphonium compounds}

The enhancement of thermal stability of phosphonium modified clay mean that it could be useful for polymers which must be processed at temperatures above that at which the ammonium clays undergo degradation. Bearing in mind that the onset temperature of the degradation of a phosphonium modified clay is about $50^{\circ} \mathrm{C}$ higher than that of ammonium clay [36], this difference could be important in the melt blending of some polymers.

In the preparation of poly(trimethylene terephthalate) (PTT) nanocomposites, elevated temperatures greater than or equal to $265^{\circ} \mathrm{C}$ are required for successful in situ intercalation 
and bulk processing. The thermal stability of PTT nanocomposite fibers obtained by in situ intercalation polymerization of dimethyl terephthalate (DMT) and 1,3-propanediol (PDO) was improved by using a thermally stable organoclay $-\mathrm{Na}^{+}-\mathrm{MMT}$ modified with dodecyltriphenylphosphonium in a way presented in Fig. 5 [37].

Fig. 5

The initial thermal degradation temperature $\left(\mathrm{T}_{\mathrm{i}}\right)$, measured as a temperature at $2 \%$ weight loss, was higher for all nanocomposites in comparison with pure polymer. However, no clear dependence of $T_{i}$ as a function of clay loading was observed and the $T_{i}$ of all PTT hybrids was in the range of $370-371^{\circ} \mathrm{C}$, regardless of the clay loading. In accordance with the increase in clay loading $(0-4 \%)$, the weight of the final residue at $600{ }^{\circ} \mathrm{C}$ was found to increase by 1 $13 \%$, which is a promising effect for flame retardation due to formation of protective surface layer.

When comparing flammability tests and thermogravimetric analysis it is necessary to be aware of the differences in experimental conditions in both tests. TG measurements are often done in inert gas atmosphere (instead of air), heat fluxes, heating rates and temperature range are quite different in thermogravimetry as compared to flammability tests - one should therefore be careful when comparing flammability and TG data.

\section{Stibonium compounds}

As it was previously mentioned, the degradation of the typical ammonium clay proceeds in two steps. In the first step, which occurs in the range of $200-400^{\circ} \mathrm{C}$, the long chain is lost as an olefin and a hydrogen replaces the alkyl group. In the second step, which commences at about $400^{\circ} \mathrm{C}$, the amine is lost and a proton is now the counterion for the clay. However, studies have shown that in case of stibonium-modified clay only a single step bridges both temperature regions. The hexadecyl group was reportedly $35 \%$ of the total mass of the stibonium cation and only $13 \%$ of the mass was lost at $400^{\circ} \mathrm{C}$ so complete degradation of this cation did not occur, unlike the case of ammonium clays where the degradation was complete. Even at $600^{\circ} \mathrm{C}$ for the stibonium cation the mass loss was only $20 \%$ and the mass fraction attributable to the cation was greater than in ammonium clay [36,38].

\section{Other modifications}


In report by Liu et al. [39], interesting results were achieved when MMT was modified with octaaminopropyl polyhedral oligomeric silsesquioxane (OapPOSS) exhibiting very high thermal stability, and using such an organoclay as filler for epoxy resin. Since one molecule of OapPOSS has eight ammonium groups it was proved that only a half of them was ionically bonded to MMT surface, and the rest was allowed to react with diglycidyl ether of bisphenol A (DGEBA) in an emulsion resulting in a DGEBA-modified clay, which was then blended with epoxy and 4,4'-diaminodiphenylmethane (DDM). The obtained hybrid material exhibited exfoliated structure with the layers effectively bonded to polymer matrix - Fig. 6.

Fig. 6

Although no significant changes were shown in the initial step of thermal degradation, the enhanced char yield was seen in the high temperature region. This effect was observed to be increasingly significant with increasing the concentration of POSS cages. The authors pointed out that the weight retention could be ascribed to POSS-MMT constituent, which was homogenously dispersed in epoxy matrix at the nanoscale. The higher char yields implied that there were fewer volatiles being released from the nanocomposites during heating.

Su et al. [40] have recently proposed new oligomeric styrene surfactants based on different ammonium, imidazolium and phosphonium salts for montmorillonite modification. Organically-treated clays containing N,N,N-trimethylpolystyrylammonium (CTMA), N,Ndimethyl-N-benzylpolystyrylammonium (CDMBA), N,N-dimethyl-Nhexadecylpolystyrylammonium (CDMH), 1,2-dimethyl-3-polystyrylimidazolium (CDMID), and triphenylpolystyrylphosphonium (CTPP) chlorides showed substantially superior thermal stability in comparison to the commonly used quaternary ammonium salts, the degradation of which begins at about $200^{\circ} \mathrm{C}$. The authors pointed that depending on the method of analysis different thermal behaviour of samples was observed. The order of organically modified clays from the most to the least thermally stable, based upon the $10 \%$ mass loss in TGA, was CTTP $>\mathrm{CDMID}>\mathrm{CDMH}>\mathrm{CTMA}>\mathrm{CDMBA}$. When DTA was used, the accessed degradation order was CTPP $>$ CDMID $>$ CTMA $>$ CDMH $=$ CDMBA. Since the boiling points of the degradation products were higher than the temperature at which they were released, the change in heat was thought as a more reliable indicator of chemical change than mass loss. The use of thermogravimetry coupled with FTIR enabled to identify the main volatile products evolved during thermal decomposition of oligomeric styrene surfactants and organomodified clays, as well as nanocomposites of these organosilicates dispersed in 
polystyrene matrix. When ammonium salt with aliphatic substituents was investigated, aliphatic $\mathrm{C}-\mathrm{H}$ absorptions were observed at the first stage of organoclay degradation. It was ascribed to 1-hexadecene that was the product of Hofmann elimination. At higher temperatures some carbonyl vibrations were seen as a result of oxidation reactions. Further temperature growth revealed aromatic $\mathrm{C}-\mathrm{H}$ vibrations, attributable to the thermal degradation of the styrene oligomer. In the degradation of the triphenylphosphine-substituted material chloride anion played an active role since the initial decomposition product determined was hydrogen chloride.

The authors indicated that the pathways of degradation are dependent on the presence of a substituent that has a $\beta$-hydrogen [40] - in that case Hofmann elimination may occur. On the other hand, in the absence of this $\beta$-hydrogen, an $\mathrm{S}_{\mathrm{N}} 2$ reaction may occur, producing the amine and the styrene-vinylbenzyl chloride copolymer. The FTIR spectra of the gases evolved during the degradation of organoclays showed no significant differences from spectra of gases coming from the surfactants except from the absence of $\mathrm{HCl}$ in the triphenylphosphine-substituted silicates spectra. In the case of modified clays different pathway by which these materials degrade was suggested. Two possible processes were described for the reaction that, according to authors, does not occur by Hofmann elimination, but rather by the displacement of the amine. Because the loss of amine that would leave an unstable benzylic carbocation as the counterion for the clay seemed to be unlikely, an alternative was proposed that surface hydroxyl groups on the clay can act as a nucleophile to displace the amine. This would give an oligomeric benzylic alcohol within the clay layers and the loss of hydroxyl group from the clay would mean that a cation is not required in the gallery space. Overall, $\mathrm{S}_{\mathrm{N}} 2$ and a $\beta$-elimination mechanisms were considered to explain the formation of products during the decomposition of the ammonium and imidazolium salts, but for triphenylphosphine, an $\alpha$-proton abstraction mechanism was suggested.

The following work of Su and Wilkie [41] reported investigations on thermal stability and degradation of nanocomposites obtained by melt blending of a wide variety of polymers with previously obtained thermally stable clays. The ammonium salts that used oligomeric styrene (COPS) or an oligomeric methacrylate (MAPS) unit, with a molecular weight of about 5000 , offered high thermal stability - mass loss of less than $7 \%$ was noted at $350^{\circ} \mathrm{C}$. Both of these new counterions contained two methyl groups, one hexadecyl group and oligomeric group responsible for enhanced thermal stability of the clay and, ultimately, of the nanocomposites. In order to enable the attachment of these units to the nitrogen, these 
oligomers also contained about 5\% of vinylbenzyl chloride. Thermogravimetric tests of clays modified with styrene oligomeric chains supported by FTIR analysis of volatile products of degradation evolved at different temperatures allowed to conclude that the presence of clay promotes the production of styrene oligomers, rather than monomer. Further, the comparison of FTIR spectra of the COPS nanocomposite with the pure polystyrene revealed that first appearance of aromatic $\mathrm{C}-\mathrm{H}$ in the degradation of PS was at higher temperature (about $380^{\circ} \mathrm{C}$ ) than that observed in COPS clay. The lower stability of the clay was considered to come from thermal instability of the nitrogen-carbon bond, leading to the more facile loss of styrene units. In turn, it was found that degradation of MAPS clay commenced at $250^{\circ} \mathrm{C}$ with the evolution of monomeric methyl methacrylate, as seen by the $\mathrm{C}-\mathrm{H}$ stretching and the carbonyl band. An aromatic $\mathrm{C}-\mathrm{H}$ peak appearing near $275^{\circ} \mathrm{C}$ was attributable to the loss of the vinylbenzyl chloride units that are attached to the clay. The authors pointed that earlier appearance of this band in comparison with pristine polymer in temperature region where the Hofmann elimination was likely to occur, may indicate $\mathrm{C}-\mathrm{N}$ bonds as the sites where the degradation was initiated. Interestingly, even at $500^{\circ} \mathrm{C}$, one could still see the carbonyl band, indicating that the clay was still undergoing degradation, while there was no longer any gas evolution found for virgin PMMA at this temperature. It was also noted that the degradation occurred in a step-wise fashion, even at ramp rate of 10 or $20 \mathrm{~K}$ per minute, contrary to the work of Kashiwagi on thermal stability of PMMA [42], where the rate of heating must have been as low as $2 \mathrm{~K}$ per minute to see the individual steps. Thus, clay must have served in some way as a template to control the pathway of the degradation.

The thermal behaviour of COPS and MAPS nanocomposites showed slightly different behaviour depending on the type of polymeric matrix nanocomposites. In the case of the styrene-containing materials, the presence of clay promotes the production of oligomer, rather than monomer. It was suggested that this change in evolved products may offer an explanation for why some polymers give large reduction in peak heat release rates while others give much smaller reductions. The PS nanocomposites with the MAPS clay degraded at lower temperatures than did virgin PS - that was connected with mostly immiscible structure of those materials. Lower initial temperature of degradation was also indicated for the polystyrene nanocomposites with COPS clay. Unlike for only COPS clay, the first peak that was seen in TG-FTIR infrared spectra of the COPS-PS nanocomposite was aromatic C$\mathrm{H}$ and not the aliphatic. The amount of clay, and hence the amount of hexadecyl units, were thought to be too small to be seen. In a case of high impact polystyrene (HIPS) nanocomposites the first appearance of the $\mathrm{C}-\mathrm{H}$ stretching frequency for both compositions 
was about $400^{\circ} \mathrm{C}$. The onset temperature of degradation was lower for the MAPS system, however, after 50\% mass loss the TG curve for MAPS-HIPS crossed that of virgin HIPS showing higher thermal stability (Fig. 7).

Fig. 7

The authors observed no influence of the degree of nano-dispersion, low in the MAPS composition and high in the COPS composition, on the degradation pathway. The TG curves of ABS and both COPS-ABS and MAPS-ABS systems showed slightly enhanced thermal stability.

Recently, different types of oligomeric surfactants, such as ammonium salt of methyl methacrylate oligomer or ammonium salt of oligomeric copolymer from lauryl acrylate and vinylbenzyl chloride, have been synthesized - Tab. 1 .

Tab. 1

Some of the new surfactants were characterised by significantly increased thermal stability (in comparison with commonly applied low molecular weight ammonium compounds) and were applied to obtain polymeric nanocomposites with enhanced thermal stability. The major advantage of this approach is the ability to design the surfactant not only with high thermal stability but also with improved compatibility with a given polymer matrix.

\subsection{Relations between conditions (methods) of nanocomposites preparation, morphology and thermal stability}

The relation between the degree of clay dispersion in polymer matrix and the thermal stability of nanocomposite material was discussed in many studies, e.g. [43,44]. The higher degree of exfoliation was achieved, the stronger enhancement of thermal resistance could be expected. The degree of exfoliation was found to depend on concentration of MMT and was followed by changes in thermal stability - the maximum of thermal stability enhancement was observed for nanocomposites with lower filler content (1-2 wt. \%) at which homogeneous exfoliation and random dispersion of nanoparticles was maintained. 
Delozier et al. [45] observed that during the preparation of polyimide (PI)/clay nanocomposites, the decomposition of the organic modifier led to the collapse of the clay particles into larger agglomerates. It was suggested that this might affect the morphological structure, properties and service life of nanocomposites, again meaning that the thermal stability of organic modifier posed significant effect on the preparation, performance and application of nanocomposites. Zheng and Wilkie [15] suggested that the enhanced thermal stability of styrene-containing (co)polymers in the presence of poly( $\varepsilon$-caprolactone) (PCL) indicated degradation inhibition. There was very little temperature difference between 10 and $50 \%$ degradation, which showed the steepness of the degradation curve. The temperatures of both 10 and $50 \%$ of degradation were enhanced for the nanocomposites relative to the virgin polymers. There was apparently a greater enhancement for the clays prepared by melt blending of the polymer than for that prepared by in situ polymerisation. This was likely due to the higher molecular weight for the processed polymer as compared to the in situ polymerised material.

In Shah and Paul's work [46], WAXD patterns revealed shifts in the peak position for the PA 6 nanocomposites and masterbatches relative to that of the pristine organoclay. These shifts apparently reflected the net result of two counteracting phenomena occurring concurrently during melt processing - intercalation of the clay galleries by the matrix polymer and degradation of the organic component of the organoclay. TG studies showed that the organic component of organoclays began to breakdown at temperatures as low as $180^{\circ} \mathrm{C}$. More degradation occurred in the masterbatch owing to heat dissipation due to combined effects of higher filler levels and higher melt viscosity of the virgin high molecular weight PA 6 . This explained the shift of the peak corresponding to a reduction of the interlayer spacing by $2-5 \AA$, as compared to the pure organoclay. In the case of low molecular weight PA 6based nanocomposites with low filler concentration, the amount of degradation was believed to be considerably less and the intercalation of polymer into the clay galleries prevailed since the peak shifts, corresponding to an increase in the d-spacing of the organoclay, stacked by $1-$ $3 \AA$.

The fundamental role of organic modifier is to decrease the cohesion forces of clay stacks and change the hydrophilic surface of clay layers into organophilic one to allow the polymer macromolecules to intercalate into MMT galleries and form stable homogeneous structure. When unmodified sodium montmorillonite is introduced into non-polar polymer matrix a microcomposite is obtained with large filler particles and no intercalation or exfoliation of polymer is usually observed. Such a structure is sometimes called 'immiscible'. 
A growing number of reports confirm that high levels of intercalation or/and exfoliation is required to achieve significant improvement of nanocomposite material properties. When clay layers are only partly intercalated/exfoliated and non-homogeneously dispersed, the performance of polymeric material could be similar to other composites with comparable load of anisotropic particles of microscopic dimensions.

Kumar et al. observed very little improvement in thermal stability of melt blended PMMA/Na ${ }^{+} \mathrm{MMT}$ composites due to limited intercalation of silicate layers [47]. Simultaneously, the nanocomposites of PMMA obtained in the same conditions with four different organoclays showed significant improvement in ability to withstand degradation in comparison to pure polymer and its microcomposites with $\mathrm{Na}^{+} \mathrm{MMT}$. The stabilization effect became larger with the extent of intercalation. In addition to the structure playing a crucial role in stabilization of polymer nanocomposites, the thermal stability of organoclay was also named as a cause of slightly lowered $\mathrm{T}_{\text {onset }}$ of nanocomposite. The organic modifier of ammonium type contained a single tallow and two ethanol groups. Due to the presence of hydroxyl groups it was highly polar organoclay with a large level of favorable miscibility with the polymer. However, the organoclays containing a single tallow modifier with a ethylhexyl group (which showed an onset of degradation at $358^{\circ} \mathrm{C}$ ) and a ditallow modifier (which showed an degradation onset of $363^{\circ} \mathrm{C}$ ) yield the best thermal characteristic of the nanocomposites compared to the organoclay containing a single tallow modifier with two ethanol groups.

Similar observations were made for poly( $\varepsilon$-caprolacton) (PCL)/clay nanocomposites obtained by in situ polymerization [48]. The lowest thermal stability was observed for PCL/Na ${ }^{+} \mathrm{MMT}$ systems, while thermal stability of organoclay/PCL nanocomposites was considerably higher. The degree of improvement depended on the extent of clay exfoliation and that in turn was connected with the ability of ammonium compound used to modify MMT to improve interphase properties. The chemical structures of alkylammonium compounds used in this study are presented in Fig. 8. The ability of compound (b) to form covalent bonds with propagating polymer chains facilitated exfoliation.

Fig. 8

The degree of intercalation/exfoliation and distribution of silicate layers was found to change with nanofiller load. Exfoliation was more likely to occur at lower clay content (about 1wt. \%) and intercalated structure was basically observed for nanocomposites with higher 
clay content. The increasing number of dispersed MMT layers per volume unit of polymer matrix causes that clay particles arrange in more regular structure.

The work by Guo and co-workers [49] on thermal properties of epoxy/MMT hybrid materials also emphasised that the dispersion of MMT is crucial for the thermal stability of nanocomposites and, as it was confirmed in previous studies [50,51] that the dispersion was influenced by the nanofiller content, the thermal stability changes were observed with increasing clay loading. When the OMMT loading was lower than $8 \mathrm{phr}$, the samples exhibited higher thermal stability than those with higher OMMT loading. Furthermore, it was found that the function of activation energy of degradation of the epoxy nanocomposites versus MMT loading shoved a maximum at 6 phr MMT (Fig. 9).

Fig. 9

The changes of the activation energy might be due to the structure evolution as the OMMT loading increases. The researchers attributed the observed phenomena to the fact that when the OMMT loading was relatively low (below $8 \mathrm{phr}$ ), exfoliated layers are the dominant structures developed in nanocomposite. The increasing OMMT content was followed by growing number of delaminated layers strengthening the retardant effects to heat and oxygen in the epoxy matrix. When the OMMT loading increased further, the nanocomposites developed an exfoliated/intercalated structure. In effect, the number of exfoliated silicate platelets, which are thought to be more effective in blocking heat and oxygen than tactoids, decreased with the OMMT loading. As a consequence, the activation energy tends to decrease when the OMMT loading was higher than 8 phr. Since the tactoids still showed the retardant effects to heat and oxygen, the activation energy of the sample with exfoliated/intercalated structure was still higher than that of the neat epoxy resin.

Studies on nanocomposite materials based on plasticized poly(L-lactide) and organomodified MMT reported an increase in thermal stability with the clay content [51]. Maximum thermal stability was obtained for a loading of $5 \mathrm{wt}$ \% in clay, however, further increases in the filler content lead to a decrease in thermal stability. A very similar thermal behaviour has been reported for EVA-based nanocomposites [50], for which optimal thermal stabilization was obtained at around $3 \mathrm{wt}$. \% filler content. Such behaviour was explained by the relative extent of exfoliation/delamination in function of the amount of organoclay. Indeed, at low filler content, exfoliation dominates, but the amount of exfoliated silicate layers is not sufficient to promote any significant improvement of the thermal stability. It was 
claimed that increasing the filler content lead to relatively more exfoliated individual particles, and increased the thermal stability of the nanocomposites. However, at filling content above $c a .5 \mathrm{wt}$. \%, complete exfoliation of such high aspect ratio silicate layers got more and more hindered because of geometrical constraints within the limited space remaining available in the copolymer matrix - and no more increase in thermal stability was detected.

For a series of polyethylene-based nanocomposites obtained by Zhai and co-workers only the system with $1 \mathrm{wt}$ \% of organoclay (PE1) had good thermal stability comparing with the pristine polymer [52]. For nanocomposites with 3 and 5 wt. \% of organoclay thermal properties have not been much changed in comparison to PE. Good dispersion of organoclay in polymer matrix in PE1 might contribute to this enhancement - its exfoliated structure was composed mainly of monolayers while MMT formed stacks at higher loadings.

In polyurethane-based nanocomposites the maximum thermal stability enhancement was observed for composition with $1 \mathrm{wt} . \%$ of dispersed organoclay which was characterized by exfoliated structure [53]. It was also observed that when the extent of exfoliation grew (the interfacial area between silicates and polyurethane increased), the glass transition temperature $\left(\mathrm{T}_{\mathrm{g}}\right)$ of the hard-segment phase of polyurethane nanocomposites increased, indicating that nano-sized silicates hindered the movement of molecules in the hard-segment phase. Further, Wang et al. showed that the elastomeric polyurethanes containing 3\% of OMMT exhibited the best thermal stability because of uniform dispersion of the organic silicate layers [54].

Similar behaviour of polypropylene nanocomposites was explained as a result of more intimate contact of polymer and clay surface and therefore stronger impact of the clay on polymer degradation process [55] [56].

On the other hand, early studies by Burnside and Giannelis have indicated that the intercalated polyimide-clay nanocomposites are more thermally stable than the delaminated nanocomposites [57]. This observation was surprising since both samples contained the same mass fraction of clay $(10 \%)$ and the clay in the delaminated nanocomposite had more homogeneous distribution.

Stretz et al. observed that the PC/MMT nanocomposites extruded by low and high shear extruders showed differences in structure [58]. The higher degree of exfoliation led to higher surface contact between PC and clay, which apparently also led to color development and molecular weight degradation. The results of flame testing indicated that processing leading to more exfoliation of MMT caused two competing effects: reduction of the peak heat release rate because of exfoliated platelets, versus degradation processes which increased the 
heat release rate. The dominate effect in PC nanocomposites with low MMT content and/or low shear samples was reduction of the initial peak heat release rate (PHRR) while the dominate effect experienced with high MMT content or high shear samples was an increased PHRR. It was indicated that the effect of intercalation versus exfoliation on thermal stability of the composite should be related to reactivity of clay surface or degradation products of the surfactant and polymer matrix. More discussion on the influence of OMMT on the thermal degradation routes of different polymers will be presented in section 3, dealing with mechanisms of thermal stability improvement.

The methods and conditions of nanocomposite preparation as well as processing are among the most important factors determining the degree of MMT layers intercalation/exfoliation and spatial arrangement that can further influence the thermal behaviour of composite material. The particular blending process which is used to prepare nanocomposites, as well as the time of annealing after the nanocomposite has been formed, can have a significant influence on the structure, and hence the properties of the nanocomposite.

When preparing polymer/clay nanocomposites using either in situ polymerization or melt intercalation, a certain temperature is needed in the processing. The decomposition temperature of OLS is a key-processing factor since processing of the nanocomposites as well as the initial melt blending of the OLS and polymer is near the thermal limits of the organic modifiers. In addition to common detrimental aspects of degradation, the resulting products may play a major and yet to be determined role in the formation of the exfoliated nanostructure.

Recently, Fornes et al. [59] investigations have confirmed that the addition of MMT tends to increase the matrix melt viscosity and, thus, the torque; however, degradation of the organic component of the organoclay leads to matrix molecular weight degradation, which lowers the Brabender torque. The study concluded that for a given organoclay, the level of polymer molecular weight reduction was greatest for nanocomposites based on high molecular weight PA 6 materials owing to the greater exposure of the surfactant to the PA 6 caused by increased levels of organoclay exfoliation. Similar matrix degradation has been reported for nanocomposites based on poly(ethylene terephthalate) (PET) [60] and polycarbonate (PC) [61] prepared by melt processing. One work observed that at 2\% MMT loading, the viscosity effects of matrix degradation apparently exceeded the intrinsic increase caused by addition of MMT, thus, shifting the curve lower [46]. At higher loadings (6.5\%), the viscosity enhancement gained by the addition of MMT, evidently exceeded the reduction resulting 
from polymer degradation in low $\mathrm{M}_{\mathrm{w}}$ PA 6 . On the other hand, at the same high loadings in high $\mathrm{M}_{\mathrm{w}}$ PA 6, the two effects seemed to offset each other resulting in little change in the torque values. Elsewhere, the 30 to $40 \%$ reduction of PA 6 molecular weight was confirmed by GPC and ${ }^{13} \mathrm{C}$ NMR analysis after injection moulding of the PA 6 nanocomposites (in situ polymerized, 5 wt. \% content of MMT modified by 12-aminolauric acid) [62].

Studies have established that the presence of acetic acid as a product of thermal degradation in processed EVA nanocomposites was confirmed by the appearance of characteristic IR shoulder around $1708 \mathrm{~cm}^{-1}$, which is a typical carbonyl absorption band of acids [63]. It was stated that the presence of acetic acid in galleries of organoclay dispersed in the polymer matrix arose from the deacylation of EVA that occured during nanocomposite compounding. Moreover, the absorption at this frequency registered for nanocomposites did not correspond with IR spectra of processed pristine polymer indicating a catalytic role of OMMT. The study also attempted to connect the changes in thermal stability of the hybrid material with its structure features modified by processing operations, such as drawing of hot melt extruded through the capillary die. The domain size of the dispersed clay phase and the formed voids were observed to decrease slightly with increasing drawing ratio (DR) - when $\mathrm{DR}=3$ the $4 \mathrm{wt} . \%$ hybrid fibre contained fine clay phases $50-60 \mathrm{~nm}$ in diameter, while for $\mathrm{DR}=9$ the domain sizes were slightly smaller $(40-50 \mathrm{~nm})$ in diameter.

More visible influence of the processing on structure properties was shown to occur when PET was used as a matrix [64]. There were evidences that higher stretching of the fibre during the extrusion lead to better dispersion of the clay and a more delaminated structure. The observed changes in structure due to processing operations might be reflected in thermal stability since the influence of MMT on initial temperature of degradation and char formation was more significant in demonstrating better dispersion in PET nanocomposites. In different work, concentration-dependent synergic effects were observed in the thermal and structural properties of poly(vinylidene fluoride-co-trifluoroethylene) (P(VDF-TrFE) nanocomposites obtained by solution blending [65,66]. For compositions of 18 and $25 \%$ OLS, the observed residue at $1000^{\circ} \mathrm{C}$ was greater than the expected value, however in the $10 \%$ OLS composition the residue at $1000^{\circ} \mathrm{C}$ was less than anticipated. The same was true for the nanocomposite films of P(VDF-TrFE) with higher OMS contents that exhibited substantial increase in weight remaining, both at $500{ }^{\circ} \mathrm{C}$ and at $1000^{\circ} \mathrm{C}$, compared to that predicted from the behaviour of the neat copolymer and OLS.

Elsewhere, studies on PP-based nanocomposites by Tidjani et al. [67] indicated that their intercalated form showed a noticeable enhancement of the thermal stability, compared to 
pure PP and polypropylene-graft-maleic anhydride copolymer (PP-g-MA). However, no significant difference was found between melt blended nanocomposites and those prepared via solution blending process. Also, the amount of non-volatile residue did not change upon irradiation for the nanocomposites though it did for PP, however the amount of non-volatile residue was greater for the melt-blended nanocomposites than for the solution blended ones. During the photo-oxidation of PP [68], crosslinking reactions were more important than chain scissions at the beginning of UV exposure, but the reverse was also true at later times in the irradiation, leading to suggestion that the crosslinking reactions that occurred upon UV irradiation were responsible for the variation in char formation. As it was expected, the onset temperature of the degradation decreased, since it depends on the strength of the bonds of molecules, which might decrease because the photo-oxidation created thermally weak bonds, e.g. in hydroperoxides and peroxides, that could initiate the thermal degradation. Since the formation of the nanocomposites appeared to have no effect on the photo-stability, the decrease of the onset temperature with UV irradiation time was to be expected. Finally, the enhancement of the thermal stability of the nanocomposites was not significantly dependent upon the particular type of organic modification that was used.

A different work observed that the $\mathrm{PP}-\mathrm{g}-\mathrm{MA}-\mathrm{MT} 2 \mathrm{EtOH}$ blends produced in air performed poorly compared to those prepared in $\mathrm{N}_{2}$ conditions - ammonium cation of the clay of organophilic montmorillonites (MT2EtOH) contained a methyl group (M), tallow (T), and two hydroxyethyl (EtOH) [69]. This led to suggestions that at the processing temperature, hydroxyethyl oxidation, which involves a hydrogen abstraction, occurred. Aldehyde and carboxylic acid might have been formed or the radical produced $\left(\mathrm{EtO}^{\circ}\right)$ could abstract a hydrogen from the polymer chain leading to a macroradical. Afterwards, the macroradical formed combined with $\mathrm{O}_{2}$ to give a peroxy radical, then hydroperoxides by $\mathrm{H}$-abstraction in the presence of air ( Fig. 10).

Fig. 10

It is worth noting that the FTIR spectra of PP-g-MA- MT2EtOH produced in air did not display any increase of the bands at $3400 \mathrm{~cm}^{-1}$, which corresponds to the hydroperoxides formation that was thought to be due to the low clay content. However, this proposed model or a similar one for the oxidative processes during preparation is highly probable. A comparison, which was done for aliphatic PA/clay composites [70], revealed that no influence 
on the thermal stability was expected for immiscible tactoid blends and a larger influence for intercalated nanocomposites than for exfoliated ones.

In other work it was found that the use of MMT that was exchanged with surfactant, whose concentration was significantly higher than the total cation exchange capacity value (CEC), intensified the surfactant decomposition during processing [71]. As a result, the dispersion of MMT in polyethylene terephthalate glycol (PETG) was changed from intercalated (for nanocomposites with MMT treated with 95 meq $\cdot(100 \mathrm{~g})^{-1}$ (MMT-95)) to immiscible for MMT with $125 \mathrm{meq} \cdot(100 \mathrm{~g})^{-1}$ (MMT-125). As a result of the loss of organic modifier during processing, platelet-to-platelet interactions occurred which result in close packing and a highly oriented structure. Despite the partially immiscible structure, the nanocomposites containing MMT-125 exhibited higher ultimate tensile strength and modulus due to high orientation of MMT platelets and forced orientation of polymer chains trapped between the oriented OLS.

For nanocomposites obtained through in situ polymerization and melt blending, significant differences could be observed in terms of initial temperature of degradation, although these nanocomposites were comparable in terms of clay concentration and structure $[15,72]$. The nanocomposites obtained through melt blending start to decompose at higher temperatures than in situ polymerized materials that are characterised by low molecular weight.

\subsection{The role of interfacial interactions, barrier and catalytic effects of montmorillonite in polymer degradation processes}

The role of interactions between macromolecules and the surface of clay layers was pointed in many studies as one of the most important factors influencing the thermal stability of polymer/montmorillonite nanocomposites. Ke et al. claimed that the nanoscale particles will show a stronger interaction with the matrices of PET, when the external temperature approaches the degradation temperature of polymeric matrix, which explained the results of enhanced degradation temperature [73]. According to Chow et al. [74], Ide and Hasegawa [75], Sathe et al. [76] and Coran et al. [77] when MAH-g-PP is added to PA 6/PP blends, the anhydride group of MAH reacts with the terminal amino group of PA 6 during melt mixing, resulting in the formation of PA 6-g-PP copolymer. Similarly, it was believed that hydrogen bonding could form between the amide group of the PA 6-g-PP copolymer and the octadecylamine group of the organoclay intercalant. It was noted that this amide-amine 
reaction could happen when the organoclay was exfoliated in the PA 6/PP matrix; subsequently, the octadecylamine (intercalant) was capable to form a chemical linkage with PA 6-g-PP copolymer. Thus, interfacial interaction gave rise to the synergic effect to properties for the MAH-g-PP compatibilized PA 6/PP nanocomposites. Pozsgay et al. [78] proved that $N$-cetylpyridinium chloride was stable at the temperature of processing and considerable weight loss was not detected below $250^{\circ} \mathrm{C}$. A major conclusion of the work was that exfoliation was dependent on surface coverage of the filler with organic modifiers and occurred only above a critical gallery distance, which corresponded to the thickness of two aliphatic chains. Although exfoliation of the silicate was governed by its organophilization and gallery structure, composite properties were dominated by interfacial interaction. In another experiment, the strong interactions between MMT and sulfonated PET ionomers were responsible for better dispersion of silicate and improved thermal resistance of the ionomer nanocomposites in comparison to nanocomposites of PET without functional groups [79].

In another study, the improvement of thermal stability of the epoxy/clay nanocomposites was attributed to the presence of the clay nanolayers, which acted as barriers to minimize the permeability of volatile degradation products out from the material [80]. As a result, it was concluded that thermal properties of nanocomposites were superior to pure epoxy resins due to a barrier property of layered silicate and an improvement of interfacial adhesion by acid-base interaction. In addition, Park et al. [81] had earlier on reported that the character of epoxy resin is an electron-donor, while the organoclay acted as an electron acceptor. Therefore, it was thought that the thermal stability of the nanocomposites was influenced by specific interactions between dispersed clay and epoxy resins.

Ma et al. [82] prepared exfoliated/intercalated nanocomposites based on two steps, i.e. preparation of treated MMT solution and solution blending with polydimethylsiloxane (PDMS). Although elemental analysis showed no residue PDMS, NMR proved that residue PDMS still existed in the solution. The residue PDMS was believed to graft onto the MMT layer surface via condensation of hydroxyl groups of PDMS and those that existed on MMT surface. Lower relaxation time of end-capped $\mathrm{CH}_{3}$ groups of alkyl ammonium grafted onto layer surface via ion exchanging in the solution showed that the layer spacing was increased significantly or even exfoliated. The TG analysis showed an increase in decomposition temperature of $70^{\circ} \mathrm{C}$ that was observed for PDMS/MMT nanocomposite while SBR/MMT nanocomposite showed only $15^{\circ} \mathrm{C}$ of decomposition temperature increased with the same amount of MMT. The nanocomposites displayed delayed decomposition temperature 
compared to the pristine polymers, which was attributed to hindered diffusion of the volatile decomposition products.

The research work by Su et al. $[40,41,83]$ showed that the type of clay and its chemical composition may have an influence on the thermal stability of nanocomposites. The observation was made that MMT was more effective in improving the thermal stability than hectorite and fluorohectorite. Moreover, at the lower amounts of clay, MMT seemed to have a synergic effect on thermal stability with tetrasodium pyrophosphate (TSPP). In turn, at low hectorite loadings, the thermal stability of the nanocomposites was lower than for PMMA and the addition of TSSP showed no effect on thermal stability in this system. The presence of unmodified fluorohectorite clay in PMMA decreased the onset temperature of thermal degradation. In that case all the DTG curves were the same, regardless of clay loadings and the presence of TSPP. It was also suggested that the improvement of the thermal stability in PMMA nanocomposites and the different behaviours of different types of smectites might be associated with reactivity of different metals with polymeric radicals ('radical trapping model') and the different thermal stability of the resulting intermediate products. Clays were able to act as free radical scavengers and traps by reacting with the propagating or initiating radicals [84]. The results indicated that both iron and aluminium contributed to the improvement of thermal stability of PMMA nanocomposites, but iron was more effective. Although it was assumed that the improvement of polymeric nanocomposites' thermal stability partially results from the barrier properties, a dependence of thermal stability on clay surface dimensions was not observed in this study.

In contrast to unmodified MMT $\mathrm{Na}^{+}$-based composites, TG profiles recorded for plasticized poly(L-lactide) (PLA) filled with unmodified $\mathrm{Na}^{+}$-MMT have reportedly shown that increasing the filler content triggers a substantial continuous decrease in thermal stability [51]. As the unmodified MMT level varied from 1 to $10 \mathrm{wt} . \%$, the maximum of TG derivative curves was shifted from $370^{\circ} \mathrm{C}$ down to $325^{\circ} \mathrm{C}$, which denoted the formation of shorter PLA chains as the clay content increased. To explain this behaviour, researchers remarked that the $\mathrm{Na}^{+}$cations present in the interlayer spaces are highly hydrated cations. At high temperature, some water release could be responsible for the PLA chain degradation by hydrolysis. According to the experimental results, at higher $\mathrm{Na}^{+}$-MMT content, chain cleavage by ester hydrolysis reaction was more pronounced, leading to the formation of much shorter PLA chains, known to degrade at lower temperature.

In other work, PMMA/Fe-MMT nanocomposites were compared with PMMA/NaMMT nanocomposites and the onset temperature of the degradation was clearly lower for the 
former than for the latter - it was connected with the catalytic effect of metal present in clay [85]. Bonding of PMMA with the formed char prevents the Fe-MMT nanocomposites from decomposing in higher temperature range and it is manifested by higher midpoint temperatures of degradation than for nanocomposites containing Na-MMT.

Also, during the modification of PVC, some metal cations present between MMT layers catalysed dehydrochlorination of PVC chains [16]. Therefore, the decomposition of alkylammonium salts and subsequent dehydrochlorination of $\mathrm{PVC}$ resin during processing might have been the cause for the degradation of PVC/organic MMT systems. When comparing PVC/Na ${ }^{+}-\mathrm{MMT}$ with PVC/organic MMT nanocomposites, it was found that the former was more stable than the latter during melt processing. Even at $10 \mathrm{wt}$ \% content of $\mathrm{Na}^{+}-\mathrm{MMT}$, the former system still kept good processing stability. In contrast, above 5 wt. \% of organic MMT content, the latter nanocomposites degraded severely and even became black in color. Therefore, a conclusion was drawn as that the existence and decomposition of alkylammonium salts play an induced role on the degradation of PVC. With the content of MMT increasing, due to clay aggregation and partial discoloration of PVC, the haze of the composites increased and the optical clarity decreased correspondingly. Therefore, it was proposed that MMT contents should be kept below $5 \mathrm{wt}$ \% in order to realize good optical clarity, processing stability and mechanical properties.

Both Trilica et al. [86] and Wang et al. [87] studied the effect of dioctylphtalate (DOP) on the structure and thermal stability of the PVC/organic MMT nanocomposites, and all agreed that organic MMT played an important role in inducing the degradation of PVC. Trilica et al. [86] took DOP as co-intercalant for organic MMT and PVC because they found alkylammonium salts between the interlayers of organic MMT, which can catalyze PVC degradation. Although DOP prevented the degradation of PVC, the MMT only acted as a plasticizer carrier and lack of specific interaction between nanofiller particles and organic modifier caused significant enhancement on mechanical and thermal properties.

Qin et al. [88] showed that the catalytic decomposition effect of MMT and the barrier effect of the silicate layers is much more evident in isothermal oxidation experiments. At $360^{\circ} \mathrm{C}$ in air atmosphere, the volatilisation rate of either the nanocomposite or the microcomposite was faster than that of pure PA 66 at the beginning; thereafter, the weight loss was slowed down in both composites compared to the pure PA 66, but with a large effect in the nanocomposite. It indicated that the nanocomposite had higher thermal stability than the microcomposite. This showed that the exfoliation of the silicate layers in polymer matrix made the barrier effect more remarkable thus decreasing the heat release rate (HRR) of PA 66 
matrix. The influence of the nanocomposite was more effective than that of the microcomposite due to the barrier effect of the exfoliated nano-structure in the nanocomposite. It was observed that the nanocomposite and the microcomposite had a shorter ignition time than pure PA 66 and the initial HRR was higher for the first $100 \mathrm{~s}$ in the combustion. This was similar to the isothermal TG profiles in air, showing that the addition of MMT can accelerate the ignition of PA 66 matrix, probably due to the catalytic decomposition effect of MMT to polymer matrix.

Most recently, Tang et al. [55] studies on PP/clay nanocomposites found out that the nanocomposites showed both a decrease in 5\% temperature loss and improved char formation. It was suggested that the probable reason was that in nanocomposites the intimate contact between the polymer molecules and the atoms of the inorganic crystalline layers was more extensive than that in a microcomposite, and at the same time, there was a catalytic role played by the layered silicates deriving from the Hofmann reaction of hexadecyltrimethyl ammonium bromide, which accelerated the charring process at the beginning of the degradation as proposed earlier on by Zanetti et al. [89]. Further studies by TEM showed the silicates were well dispersed (exfoliated) in the polymer matrix. The $\mathrm{T}_{\max }$ and char residue of nanocomposites tended to increase compared with those of microcomposite and polymer matrix. Remarkable effects found on the nanocomposites were associated to an ablative reassembling of the silicate layers which may occur on the surface of the nanocomposites creating a physical protective barrier.

\section{The mechanisms of thermal stability improvement by nanodispersed montmorillonite layers}

The mechanism of the improvement of thermal stability in polymer nanocomposites is not fully understood yet. It is usually well accepted that the improved thermal stability for polymer/clay nanocomposites is mainly due to the formation of char which hinders the outdiffusion of the volatile decomposition products, as a direct result of the decrease in permeability, usually observed in exfoliated nanocomposites [36,70,90-92]. Despite this, the exact degradation mechanism is currently not clear - such a behaviour is probably associated with the morphological changes in relative proportion of exfoliated and intercalated species with the clay loading. At low clay loading ( $c a .1 \mathrm{wt}$. \%), exfoliation dominates but the amount of exfoliated nanoclay is not enough to enhance the thermal stability through char formation [90]. When increasing the clay concentration (2-4 wt. \%), much more exfoliated clay is 
formed, char forms more easily and effectively and consequently promotes the thermal stability of the nanocomposites. At even higher clay loading level (up to $10 \mathrm{wt} . \%$ ), the intercalated structure is the dominant population and, even if char is formed in high quantity, the morphology of the nanocomposite probably does not allow for maintaining a good thermal stability. However, it is known that the chemical nature of the polymers, the type of clays and their modification route play an important role in their degradation behaviour. Therefore, care should be taken when attempting to generalize conclusions drawn from a PA 11-based system to nanocomposites formed from another polymer system [93].

Comparing the results obtained over the thermal degradation, it was evident that the effect of exfoliated silicate layers was more pronounced during thermal oxidation than thermal degradation. Therefore, the mass loss decomposition started almost at the same temperature for PP-g-MA/octadecyl trimethyl amine-modifed MMT (PP-g-MA-OD3MA) and $\mathrm{PP}-\mathrm{g}-\mathrm{MA}$, but, later on, a clear shift up to $250^{\circ} \mathrm{C}$ was displayed - such behaviour is typical for a barrier effect due to the remaining silicate layers. Consequently, it was concluded that they acted as diffusion barriers for the oxygen. Thus, the kinetics of decomposition was delayed with similar starting temperatures of decomposition. Therefore, for the nanocomposite beside the thermo-oxidative degradation, thermal decomposition seemed to be probable due to the presence of silicate layers that hinder the diffusion of oxygen. Then, change in the chemical reaction was assumed as a significant difference in the decomposition of the real nanocomposite in comparison to $\mathrm{PP}-\mathrm{g}-\mathrm{MA}$ and the microcomposites, respectively. These results and interpretation are in good correspondence with the results found for the thermal and thermal oxidative decomposition of poly(vinyl acetate)-layered silicate nanocomposites [94]. Comparing the derivative curves, it was observed that PP-g-MAOD3MA decomposed via a single step degradation process. Similar to the thermal behaviour, the thermo-oxidative decomposition did not show an enhanced char formation due to the presence of clay in the polymer matrix. Therefore, not only a significant heat shielding effect but also a gradual decomposition of polymer chains in close contact with clay layers were improbable. Even further, studies have shown that the lower flammability of polymer/clay nanocomposites is not due to retention of a large fraction of fuel, but due to the formation of carbonaceous char in the condensed phase [70,95-98]. The nanodispersed lamellae of clay in polymer matrix result qualitatively in a spatially more uniform and thicker char during decomposition.

The accelerated char formation due to presence of dispersed montmorillonite layers was again indicated as a mechanism of thermal stability improvement in the Agag and 
Takeichi [99] development on stearyl ammonium modified MMT-based nanocomposites. The studies to monitor the thermal properties of the MMT nanolayers dispersed in the polybenzoxazine matrix revealed that only very small amount of clay was effective to improve the weight residues for nanocomposites. The char yield at $800^{\circ} \mathrm{C}$ increased by $c a$. $20 \%$ with 5\% MMT content in the nanocomposite. The thermal stability of the nanocomposites was improved by the presence of dispersed MMT nanolayers in comparison with the pristine polybenzoxazine. This enhancement in the thermal properties was also ascribed to the presence of the MMT nanolayers, which acted as barriers to minimize the permeability of volatile degradation products out from the material. In addition, isothermal TGA was performed to give more evidence about the improvement of the thermal stability of polybenzoxazine in the presence of MMT. The nanocomposites showed a delayed decomposition compared with the pristine polybenzoxazine due to the homogeneous distribution of the silicate sheets into the polymer matrix and consequently improved the thermal properties of the nanocomposites as explained before. The improved char formation was again reported by Becker et al. [100] since the nanocomposites showed slightly reduced thermal stability, as indicated by a slight decrease in onset of degradation, whilst the final char concentration increased for greater organoclay concentrations.

Interesting observations concerning char formation were made in Kashiwagi and coworkers work [101]. They have noticed differences in a sequence of events during nonflaming gasification of pure polyamide and PA/MMT nanocomposites containing 2 and $5 \mathrm{wt}$. $\%$ of nanofiller at a heat flux of $50 \mathrm{~kW} / \mathrm{m}^{2}$. With increasing amount of montmorillonite the intensity of protective floccules formation on the sample surface also increased. The analysis of the protective floccules, collected at various sample mass losses, showed that up to $80 \%$ by mass of the floccules consisting of clay particles. The remaining $20 \%$ consisted of thermally stable organic components with possible graphitic structure. Furthermore, clay particles were stacked and the d-spacing of the clay platelets was in the range of 1.3-1.4 $\mathrm{nm}$. Two possible mechanisms were possible that led to the accumulation of the initially well-dispersed clay particles on the burning/gasifying sample surface. One was migration of the polymer resin from the surface by pyrolysis with de-wetted clay particles left behind and further an aggregation of MMT layers to form stacks after the degradation of the organic treatment on the clay surface had made them more hydrophilic and less compatible with the resin. Another mechanism is the transportation of clay particles pushed by numerous rising bubbles of degradation products and the associated convection flow in the melt from the interior of the sample toward the sample surface. Simultaneously, bubbles pushed the accumulated clay 
particles outward from the area where they were burst. This led to formation of the island-like structure of the sample surface instead of forming a continuous net-like structure of a clay filled protective layer. Therefore, both PA 6/clay nanocomposites did not produce sufficient amounts of protective floccules to cover the entire sample surface and vigorous bubbling was observed over the sample surface which was not covered by the protective floccules.

On the other hand, Tidjani et al. [69] investigations on PP-g-MA layered silicate nanocomposite suggested that the presence of the clay exerted only a minor effect on the thermal degradation. This result corresponded well to the residues found, which hardly showed any additional residue forming due to an enhanced char forming of the polymer matrix in the presence of clay. In fact, this effect was well below 5\% additional char formation. Consequently, the residue might not have been able to insulate the underlying polymer from the heat effectively, thus, a heat shielding effect was of minor importance in the investigated systems as well as a contribution of alternative polymer decomposition due to interactions with the clay layer that was typical for confined intercalated structures. It was concluded that the clay layers worked as diffusion barriers in the exfoliated systems of PP-gMA layered silicate nanocomposite and slightly delayed the decomposition process.

Furthermore, the mobility of early decomposition products seemed to be hindered, whereas for increasing conversion no influence on the decomposition was proven.

Vaia et al. [102] experimental work observed that relatively tough, inorganic char formed during ablation of the poly( $\varepsilon$-caprolactam) nanocomposites. This refractory char resulted in an order-of-magnitude decrease in the mass loss rate relative to the neat polymer, even for as little as 2 wt. \% exfoliated layered silicate. This enhanced ablative performance was not related to an alteration of decomposition kinetics but instead was associated with the presence of the silicate layers. The work reported that the presence of the exfoliated silicate only minutely altered nonisothermal decomposition kinetics in poly( $\varepsilon$-caprolactam), which was dominated by chain scission through the alkyl amide bond via a free radical mechanism. This contrasted other nanocomposites, which exhibited improved nonisothermal decomposition. Thus, the role of the dispersed silicate in thermal decomposition of a polymer depended critically on the specific mechanisms associated with the polymer degradation reaction. The improvement in ablative performance of these nanocomposites relative to the neat polymer or traditional filled systems with a comparable inorganic fraction was associated with the char-forming characteristics of the nanocomposites. The spatially uniform distribution of aluminosilicate layers on the nanoscale resulted in the formation of a uniform inorganic char layer at a relatively low fraction of inorganic component. This nanoscopic 
morphology was comparable to the length scale of the decomposition and char-forming reactions determined by the temperature profile and the diffusivities of the reactants and products. Thus, the reported work suggested that a uniform supply of inorganic precursor to the char was available during decomposition. In contrast, the localization of inorganic species on the micron-scale associated with traditional filled systems required a higher loading for the formation of a uniform inorganic char at the surface [102]. At loading fractions comparable to the nanocomposites, large regions void of inorganic precursor were present resulting in locally, nonuniform erosion rates leading to rough surfaces more susceptible to mechanical degradation. The type of organic modification on the silicate surface and specific interactions between the polymer and the silicate surface such as end-tethering of a fraction of the polymer chains through ionic interactions to the layer surface only minutely altered the ablative or char-forming behaviour of the nanocomposites. Layer concentration, size and degree of dispersion were the dominant factors. The report suggested that the enhancement in ablative performance should be a general observation for exfoliated polymer layered silicate nanocomposites and may also be observed for other nanocomposite systems, such as dispersed nanoparticulate, e.g., $\mathrm{TiO}_{2}, \mathrm{SiO}_{2}$ - polymer blends. The formation of the protective layer, the char-forming reactions and ablative reassembly of clay during thermal degradation and combustion has also been observed even for polymers that are not showing char forming tendencies, such as PE and PP. Generally, char formation during polymer degradation is a complex process; it occurs in several steps, which include conjugated double bond formation, cyclisation, aromatization, fusion of aromatic rings, turbostratic char formation and, finally, graphitisation [63].

The complex oxidation chain reactions of organic molecules were schematically expressed by Benson and Nogia [103]. According to proposed mechanism at temperature below $200^{\circ} \mathrm{C}$ the oxidation of $\mathrm{PE}$ and EVA involves free-radical chain reactions and the main products are hydroperoxides and oxygenated species (routes A1 and A2 of Fig. 11).

\section{Fig. 11}

At this temperature, the abstraction of $\mathrm{H}$ from $\mathrm{R}^{\circ}$ to give $\mathrm{HO}_{2}{ }^{\circ}$ and olefin (routes $\mathrm{B} 1$ and $\mathrm{B} 2$ ) is at least 200 times slower than the addition of $\mathrm{O}_{2}$ to $\mathrm{R}^{\circ}$ to give $\mathrm{RO}_{2}{ }^{\circ}$. Above $250^{\circ} \mathrm{C}$, the very slow step B becomes rate determining since mechanism A becomes reversible. As a result, above $300^{\circ} \mathrm{C}$ the initial rate of oxidation of the polymer begins to decrease. Above $480^{\circ} \mathrm{C}$, where the rate of oxidation picks up again, the $\mathrm{H}_{2} \mathrm{O}_{2}$ can provide a secondary radical source 
similarly as ROOH. In normal condition process A prevails and the thermo-oxidation causes chain scission with subsequent volatilization of the polymer. Zanetti [104] noticed that the mechanism B seemed to prevail in the polymer nanocomposites where an enhanced aromatization and a reduced rate of oxidation were observed. Oxidative dehydrogenation (route B) leads to conjugated double bond sequences that transform the polymer in a conjugated polyene, similar to those formed by thermal deacylation of poly(vinyl acetate) or dehydrochlorination of poly(vinyl chloride) that occurs on heating, yielding aromatized thermally stable charred structures through inter- and intra-molecular Diels-Alder reactions [29]. The thermal behaviour of polymeric nanomaterials in oxidative environment is influenced by the hindered penetration of oxygen through silicate layers that protect the bulk of the polymer matrix.

Hence, Gilman et al. [70,92] reported that the layered silicates appeared to enhance the performance of the char layer, which acted as an insulator and mass transport barrier and therefore reduced the mass loss rate and improved flammability and thermal stability. Yano et al. [105] experimental and theoretical work reported that in PI/clay nanocomposites, the permeability coefficient of volatile gases, such as water vapour and $\mathrm{He}$, was remarkably decreased. The observed 'labyrinth effect' is also thought to play important role in thermal stability improving of polymer/MMT nanocomposites since composite material having poor dispersity of MMT usually exhibit no thermal improvement or the effect is poor in comparison to well exfoliated or intercalated nanocomposites. For example, Lee et al. [93] investigated the thermal stability of aliphatic PI/clay nanocomposites and found that an immiscible PI/clay mixture (i.e. conventional mixture), which contains the same amount of silicate as the intercalated nanocomposites, showed no enhancement in the thermal stability. The structural features of microcomposite where no barrier effect was observed in contrast to intercalated nanocomposite material played a crucial role in polymer stabilization. Burnside and Giannelis [57] also reported similar results for polydimethylsiloxane (PDMS)/clay nanocomposites. They found that the PDMS/clay nanocomposites showed the decomposition temperature higher than the pure PDMS elastomer due to the hindered diffusion of volatile degradation species from the nanocomposites, confirming Yano et al. [105] findings. Studies on the thermal decomposition behaviour of pristine polypropylene (PP) and compatibilizers modified PP/clay nanocomposites found out that the onset degradation temperatures of the nanocomposites vary from $205^{\circ} \mathrm{C}$ for maleic anhydrite (MA) modified PP (with MA content of 4 wt. \% modified composite) to $375^{\circ} \mathrm{C}$ for $\mathrm{PP} /$ clay nanocomposites [106]. The improvement in thermal stability for PP nanocomposites was associated to the 
interactions between organic and inorganic phases. It was also concluded that individual layers of exfoliated clay platelets acted as insulator, and the formation of tortuous path between layers also inhibited the passage of volatile degradation products, hence enhancing the thermal stability of clay-containing composites. Zhu et al. [107] study on PP/clay nanocomposites found out that the structural iron in the dispersed clay also acted as a trap for radicals and hence improved thermal stability.

The changes in activation energy of pure LLDPE and LLDPE/MMT nanocomposites obtained from isoconversional kinetic analysis revealed some clues on the mechanism of thermal stability improvement [108]. The activation energy of the LLDPE nanocomposite gradually increased from 60 to $150 \mathrm{~kJ} / \mathrm{mol}$ during the first degradation stage $(\alpha<0.6)$, which indicated that the process kinetic is limited by peroxide radical decomposition. At the following stage $(\alpha>0.6)$, the activation energy rapidly increased to around $220 \mathrm{~kJ} / \mathrm{mol}$, which was similar to the activation energy obtained by degradation of PE under inert gas, as reported in the literature [109]. These observations indicated that the rate-limiting step in the thermooxidative degradation of LLDPE nanocomposites have changed from peroxide radical decomposition to random scission decomposition. By the comparison between thermal behaviour of layered double hydroxides (LDH) and MMT nanocomposites it was found that the MMT nanocomposites had lower effective activation energy at the early stages of thermal degradation because the presence of MMT layers could catalyze the dehydrogenation of LLDPE molecule. After that, ceramic-carbonaceous layers formed on the surface of the material might act as an efficient mass transport barrier. It was concluded that the nanodispersed inorganic layers cause an anaerobic condition in the samples, as indicated by the change of rate-limiting step in the thermo-oxidative degradation from peroxide radical decomposition to random scission decomposition. These results were consistent with the barrier model mechanism, which suggests that the inorganic layers play a barrier effect on the diffusion of oxygen from gas phase into the nanocomposite's inferior.

The investigation report by Chang et al. [110] on PET nanocomposites remarked other phenomenon playing role in improving the thermal stability of hybrid material apart form the mass transport barrier mechanism to the volatile products generated during decomposition. On the basis of the fact that clays have good thermal stability the authors concluded that the introduction of inorganic components into organic polymers could improve their thermal stabilities due to the heat insulation effect of the clay layers. For SAN/MMT system, which did not form an enhanced amount of char, the insulative effect of MMT nanoparticles was 
also evidenced by the reduction of backside temperature of a sample in cone calorimetry measurements [111].

In another development, Lee et al. [112] noted that, when polyaniline (PANI) content was above 12.5 wt. \%, in PANI/ $\mathrm{Na}^{+}-\mathrm{MMT}$ conducting nanocomposites, the excess amount of PANI chains reside mainly outside the silicate layers of $\mathrm{Na}^{+}-\mathrm{MMT}$ (free PANI chains) and that the PANI chains intercalated between the silicate layers and the free PANI chains coexisted in the PANI/Na ${ }^{+}$-MMT nanocomposites. Thus, it was proposed that the thermal decomposition of the nanocomposites occurred in both confined and free states at the same time. However, the contributions from the free PANI chains were more significant for thermal decomposition because these chains in the PANI/ $\mathrm{Na}^{+}-\mathrm{MMT}$ nanocomposites are more exposed to the heating when compared with the PANI chains intercalated between the silicate layers. It was concluded from the relative shift of temperature at the maximum of the DTG curve that, even in the higher PANI content range, where a large portion of free PANI chains existed, the shielding effect of the silicate layer during the thermal degradation of PANI became sufficiently dominant, even with $20 \mathrm{wt} . \%$ of $\mathrm{Na}^{+}$-MMT content, and then increases gradually at $\mathrm{Na}+-\mathrm{MMT}$ contents above it. In another work, careful comparison of thermal behaviour of PANI/ $\mathrm{Na}^{+}-\mathrm{MMT}$ nanocomposite (with intercalated structure) with that of the mixture, suggested that the intercalated nanocomposite system was more thermally stable than the simple mixture of unmodified clay and PANI and the pure PANI [113]. It was emphasized that the silicate layer with a high aspect ratio effectively acted as a barrier for thermal decomposition of PANI chains in PANI/Na ${ }^{+}$-MMT nanocomposite compared with a physical mixture. As a result, it was evident that the intercalated nanostructure in polymer/layered silicate nanocomposites was crucial to enhance the thermal stability.

Blumstein [114] showed that in poly(methyl methacrylate) (PMMA)/layered silicates (clay) nanocomposites, the PMMA placed between the interlayer spacings of MMT was resistant to the thermal degradation under the condition that would otherwise completely degrade pure PMMA. Here this enhanced thermal stability of the PMMA nanocomposite was attributed to the restricted thermal motion of the PMMA in the gallery of clay (i.e. improved barrier property).

A series of works performed by Vyazovkin et al. has been dedicated to the study of the thermal degradation process of PS-based nanocomposites as well as changes in nanostructure influencing the stability enhancement. It was demonstrated that montmorillonite layers enhance the thermal stability of polymers via suppression of the molecular mobility. The investigated PS-based system was obtained via surface-initiated polymerization where 
montmorillonite intercalated by monocationic azobisisobutyronitrile-analogue molecule was used as an radical initiator and growing polymer chains were grafted onto MMT surface through initiator molecule. The kinetic analysis of thermal degradation of PS-based nanocomposites showed that the whole process demonstrated a markedly larger effective activation energy as compared to that of pure PS. The variation of activation energy $E_{\alpha}$ versus degree of conversion indicated a change in limiting step of the process. Moreover, on the basis of DSC measurements it has been found that the heat of degradation process in nitrogen for PS-clay nanocomposites with $0.5 \mathrm{wt}$. \% clay content was $-670 \mathrm{~J} \cdot \mathrm{g}^{-1}$ as opposed to $-990 \mathrm{~J} \cdot \mathrm{g}^{-}$ ${ }^{1}$ for PS [115]. The change in the total heat suggested a possible alternation of the degradation mechanism that may be related to changing a branching ratio of the individual channels as well as to the formation of new degradation products. It should be stressed that barrier and radical trapping models successfully explain why the degradation of polymer-clay systems is slower, but they do not offer straightforward ways of explaining the changes in the thermal effect as well as of predicting changes in the degradation mechanism. Vyazovkin et al. developed a new model that linked the increased thermal stability of PS-clay grafted nanocomposites to the changes in polymer nanostructure and chain mobility. Using the DSC and DMA methods to measure the relaxation kinetics it was found that the glass transition in PS-nannocomposites had a significantly larger activation energy than that in PS. The obtained relaxation data indicated the long chain molecular motion in the PS-clay nanocomposite encountered a markedly larger energy barrier than pristine PS. That is at the same temperature the nanocomposite should have lower molecular mobility than the virgin polymer. In other words, translational motion in the polymer-clay system required a larger degree of cooperativity. The extra cooperativity in polymer-clay grafted nanocomposites was introduced by the clay sheets that anchor several polymer chains, making their individual motions mutually dependent. Further, on the basis of the heat capacity data, the volume of cooperatively rearranging regions for nanocomposites was found to be 1.8 times larger than that for virgin PS [116]. Because the molecular mobility is the major factor that contributes to the transport of reactive species within the polymer, the nanocomposites are likely to have lower reactivity and, therefore, greater chemical and thermal stability than virgin polymer. Regardless of the increased activation energy of glass transition, measured in lower temperature experiments, the increase in viscosity appears to be commonly observed for various polymer-clay nanocomposites and has an impact on the kinetics of chemical reactions that occur in viscous media [117]. 
The very recent results concerning the thermal stability of a number of polymers have put forward the idea that the clay qualitatively affects the polymer degradation [118-122]. The different efficiency of MMT in improving the thermal stability of polymers was considered in terms of the complexicity of degradation pathways or in terms of radical stability. When there is more than one degradation pathway, as it is in the case of PS, where both monomer and oligomer are produced, the presence of the clay can promote one degradation pathway at the expense of another. If the pathway which is promoted leads to higher molecular weight material, then the polymer is degraded more slowly than it would be in the absence of the clay. However, if there is only a single degradation pathway (or more theoretically probable ways but leading to production of the same products, as for instance in the case PMMA) the clay cannot promote an evolution of different degradation products. Referring to the radical stability, if the stability of radical species produced during thermal decomposition of polymer is high - they exhibit longer lifetimes - the probability that they will undergo secondary intermolecular reactions, especially radical recombination reactions, is also high - the role of the clay is then to prevent mass transport from the bulk and to permit radical recombination reactions, exerting thus a stabilization effect in the polymer/layered silicate nanocomposite.

\section{Conclusions}

The results of recent research indicate that the introduction of layered silicates into polymer matrix causes an increase in thermal stability. Due to characteristic structure of layers in polymer matrix, their shape and dimensions close to molecular level several effects have been observed that can explain the changes in thermal properties. Experimental results have shown that layers of MMT are impermeable for gases meaning that both intercalated and exfoliated structure get created in a labyrinth for gas penetrating the polymer bulk. Thus, the effect of 'labyrinth' limits the oxygen diffusion inside the nanocomposite sample. Similarly in the samples exposed to high temperature the MMT layers restrain the diffusion of gasses evolved during degradation. Moreover, MMT layers are thought to reduce heat conduction. In the presence of MMT layers strongly interacting with polymer matrix the motions of polymer chains are limited. This effect brings additional stabilization in the case of polymer/MMT nanocomposites. Nanocomposites exhibit more intensive char formation on the surface of sample exposed to heat. It protects the bulk of sample from heat and decreases the rate of mass loss during thermal decomposition of polymeric nanocomposite material. More intensive formation of a char in comparison with pristine polymers can be indicative of 
improved flame resistance. The char formed in a case of nanocomposites performs higher mechanical resistance and therefore nanocomposites are considered as a potential ablative. The phenomena mentioned above are thought to retard the thermal decomposition processes through reducing the rate of mass loss - unfortunately, few works have been dedicated on the study of gases evolved from nanocomposites during thermal and thermo-oxidative degradation.

The heat barrier effect could also provide superheated conditions inside the polymer melt leading to extensive random scission of polymer chain and evolution of numerous chemical species which, trapped between clay layers, have more opportunity to undergo secondary reactions. As a result, some degradation pathways could be promoted leading to enhanced charring. It is also suggested that the effect of more effective char production during thermal decomposition of polymer/clay nanocomposites may be derived from a chemical interaction between the polymer matrix and the clay layer surface during thermal degradation. Some authors indicated that catalytic effect of nanodispersed clay is effective in promoting charforming reactions. Nanodispersed MMT layers were also found to interact with polymer chains in a way that forces the arrangement of macrochains and restricts the thermal motions of polymer domains. Generally, the thermal stability of polymeric nanocomposites containing MMT is related to the organoclay content and the dispersion. The synthesis methods influence the thermal stability of polymer/MMT nanocomposites as long as they are governing the dispersion degree of clay layers. Currently, extensive research is devoted to the synthesis of novel thermally-stable modifiers (including oligomeric compounds) that can ensure good compatibility and improve the nanocomposite thermal stability due to low migration characteristics. 


\section{References}

[1] S.B. Hendricks, J. Phys. Chem. 45 (1941) 65.

[2] B.K.G. Theng, Chemistry of Clay-Organic Reactions, Wiley, New York 1974.

[3] L.A. Utracki, Clay-Containing Polymeric Nanocomposites, Rapra, Shawbury 2004.

[4] J. Njuguna, K. Pielichowski, Adv. Eng. Mater. 5 (2003) 769.

[5] J. Njuguna, K. Pielichowski, Adv. Eng. Mater. 6 (2004) 193.

[6] J. Njuguna, K. Pielichowski, Adv. Eng. Mater. 6 (2004) 204.

[7] S. Sinha Ray, M. Okamoto, Prog. Polym. Sci. 28 (2003) 1539.

[8] J.K. Pandey, K.R. Reddy, Polym. Degrad. Stab. 88 (2005) 234.

[9] K. Pielichowski, L. Stoch, J. Therm. Anal. 45 (1995) 1239.

[10] K. Pielichowski, A. Leszczynska, Polimery 51 (2006) 60.

[11] T. Liu, K.P. Lim, W.C. Tjiu, K.P. Pramoda, Z.-K. Chen, Polymer 44 (2003) 3529.

[12] W. Xie, Z. Gao, K. Liu, W.-P. Pan, R. Vaia, D. Hunter, A. Singh, Thermochim. Acta 339 (2001) 367.

[13] R. Greene-Kelly, in: R.C. Mackenzie, (Ed.), The Differential Thermal Investigation of Clays, Mineralogical Society London 1957.

[14] W. Xie, Z.M. Gao, W.P. Pan, D. Hunter, A. Singh, R.A. Vaia, Chem. Mater. 13 (2001) 2979.

[15] X. Zheng, C.A. Wilkie, Polym. Degrad. Stab. 82 (2003) 441.

[16] C. Wan, X. Qiao, Y. Zhang, Y. Zhang, Polym. Test. 22 (2003) 453.

[17] J.M. Hwu, G.J. Jiang, Z.M. Gao, W. Xie, W.P. Pan, J. Appl. Polym. Sci. 83 (2002) 1702.

[18] P.A. Ciullo, Chimica Oggi - Chem. Today March/April (1997).

[19] R. Greene-Kelly, Mineral. Mag. 30 (1955) 604.

[20] M.A. Osman, M. Ploetze, P. Skrabal, J. Phys. Chem. B 108 (2004) 2580.

[21] M.A. Osman, M. Ploetze, U.W. Suter, J. Mater. Chem. 13 (2003) 2359.

[22] Z.M. Liang, J. Yin, H.J. Xu, Polymer 44 (2003) 1391.

[23] Z.-M. Liang, C.-Y. Wan, Y. Zhang, P. Wei, J. Yin, J. Appl. Polym. Sci. 92 (2004) 567.

[24] J.H. Adams, J. Polym. Sci. Part A-I 8 (1970) 1077.

[25] K. Stoeffler, P.G. Lafleur, J. Denault, in: Proceedings of 3rd International Symposium on Polymer Nanocomposites Sci. and Technol., Quebec, Canada, Sept. 28-30 2005.

[26] L.A. Utracki, in: Proceedings of 3rd International Symposium on Polymer Nanocomposites Sci. and Technol., Quebec, Canada, Sept. 28-30 2005.

[27] Z.-M. Liang, J. Yin, H.J. Xu, Polymer 44 (2003) 1391.

[28] C.S. Triantafillidis, P.C. LeBaron, T.J. Pinnavaia, J. Solid State Chem. 167 (2002) 354.

[29] W.H. Awad, J.W. Gilman, M. Nydena, R.H. Harris Jr., T.E. Sutto, J. Callahan, P.C.

Trulove, H.C. DeLongc, D.M. Fox, Thermochim. Acta 409 (2004) 3.

[30] J.W. Gilman, W.H. Awad, R.D. Davis, J. Shields, R.H. Harris Jr, C. Davis, A.B.

Morgan, T.E. Sutto, J. Callahan, P.C. Trulove, H.C. Delong, Chem. Mater. 14 (2002) 3776.

[31] H. Ngo, K. Le Compte, L. Hargens, A.B. Mc Ewen, Thermochim. Acta 97 (2000) 357.

[32] C.G. Begg, M.R. Grimmett, P.D. Wethey, Aust. J. Chem. 26 (1973) 2435.

[33] B.K.M. Chan, N.-H. Chang, M.R. Grimmett, Aust. J. Chem 30 (1977) 2005.

[34] A.N. Kost, I.I. Grandberg, Adv. Heterocycl. Chem. 6 (1966) 417.

[35] R.T. Carlin, J. Fuller, Molten Salts: From Fundamentals to Applications

in NATO Science Series, M. Gaune-Escard (Ed.), Kluwer, Dordrecht 2002.

[36] J. Zhu, A.B. Morgan, F.J. Lamelas, C.A. Wilkie, Chem. Mater. 13 (2001) 3774.

[37] J.-H. Chang, S.J. Kim, S. Im, Polymer 45 (2004) 5171. 
[38] W. Xie, Z. Gao, W.-P. Pan, R. Vaia, D. Hunter, A. Singh, Polym. Mater. Sci. Eng. 83 (2000) 284.

[39] H. Liu, W. Zhang, S. Zheng, Polymer 46 (2005) 157.

[40] S. Su, D.D. Jiang, C.A. Wilkie, Polym. Degrad. Stab. 84 (2004) 269.

[41] S. Su, C.A. Wilkie, Polym. Degrad. Stab. 83 (2004) 347.

[42] T. Kashiwagi, A. Inaba, J.E. Brown, K. Hatada, T. Kitayama, E. Masuda, Macromolecules 19 (1986) 2160.

[43] S.K. Srivastava, M. Pramanik, H. Acharya, J. Polym. Sci.: Part B: Polym. Phys. 44 (2006) 471.

[44] A. Riva, M. Zanetti, M. Braglia, G. Camino, L. Falquic, Polym. Degrad. Stab. 77 (2002) 299.

[45] D.M. Delozier, R.A. Orwoll, J.F. Cahoon, N.J. Johnston, J.G. Smith Jr., J.W. Connell, Polymer 43 (2002) 813.

[46] R.K. Shah, D.R. Paul, Polymer 45 (2004) 2991.

[47] S. Kumar, J.P. Jog, U. Natarajan, J. Appl. Polym. Sci. 89 (2003) 1186.

[48] B. Lepoittevin, N. Pantoustier, M. Devalckenaere, M. Alexandre, D. Kubies, C. Calberg, R. Jérôme, P. Dubois, Macromolecules 35 (2002) 8385

[49] B. Guo, D. Jia, C. Cai, Eur. Polym. J. 40 (2004) 1743.

[50] S.T. Lim, Y.H. Hyun, H.J. Choi, M.S. John, Chem. Mater. 14 (2002) 1839.

[51] M.-A. Paul, M. Alexandre, P. Degee, C. Henrist, A. Rulmont, P. Dubois, Polymer 44 (2003) 443.

[52] H. Zhai, W. Xu, H. Guo, Z. Zhou, S. Shen, Q. Song, Eur. Polym. J. 40 (2004) 2539.

[53] Y.I. Tien, K.H. Wei, J. Appl. Polym. Sci. 86 (2002) 1741.

[54] J. Wang, Y. Chen, J. Wang, J. Appl. Polym. Sci. 99 (2006) 3578.

[55] Y. Tang, Y. Hu, L. Song, R. Zong, Z. Gui, Z. Chen, W. Fan, Polym. Degrad. Stab. 82 (2003) 127.

[56] H. Qin, S. Zhang, C. Zhao, M. Feng, M. Yang, Z. Shu, S. Yang, Polym. Degr. Stab. 85 (2004) 807.

[57] S.D. Burnside, E.P. Giannelis, Chem. Mater. 7 (1995) 1597.

[58] H.A. Stretz, J.H. Koo, V.M. Dimas, Y. Zhang, Polym. Prepr. 42 (2001) 50.

[59] T.D. Fornes, P.J. Yoon, D.R. Paul, Polymer 44 (2003) 7545.

[60] J.C. Matayabas Jr, S.R. Turner, in: T.J. Pinnavaia, G.W. Beall, (Eds.), Polymer-Clay Nanocomposites, Wiley New York 2001.

[61] P.J. Yoon, D.L. Hunter, D.R. Paul, Polymer 44 (2003) 5341.

[62] R.D. Davis, J.W. Gilman, D.L. Vanderhart, Polym. Degrad. Stab. 79 (2003) 111.

[63] S. Levchik, C. Wilkie, in: A. Grand, C. Wilkie, (Eds.), Fire Retardancy, Marcel Dekker

New York 2000.

[64] J.-H. Chang, S.J. Kim, Polym. Bull. 52 (2004) 289.

[65] P. Cebe, J. Runt, Polymer 45 (2004) 1923.

[66] F. Gong, M. Feng, C. Zhao, S. Zhang, M. Yang, Polym. Degrad. Stab. 84 (2004) 289.

[67] A. Tidjani, C.A. Wilkie, Polym. Degrad. Stab. 74 (2001) 33.

[68] A. Tidjani, J. Appl. Polym. Sci. 64 (1997) 2497.

[69] A. Tidjani, O. Wald, M.-M. Pohl, M.P. Hentschel, B. Schartel, Polym. Degrad. Stab. 82 (2003) 133.

[70] J.W. Gilman, Appl. Clay Sci. 15 (1999) 31.

[71] A. Ranade, N. D'souza, C. Thellen, J.A. Ratto, Polym. Int. 54 (2005) 875.

[72] G. Chigwada, D. Wang, C.A. Wilkie, Polym. Degrad. Stab. 91 (2006) 848.

[73] Y. Ke, C. Long, Z. Qi, J. Appl. Polym. Sci. 71 (1999) 1139.

[74] W.S. Chow, Z.A. Mohd Ishak, J. Karger-Kocsis, A.A. Apostolov, U.S. Ishiaku, Polymer $44(2003) 7427$. 
[75] F. Ide, A. Hasegawa, J. Appl. Polym. Sci. 18 (1974) 963.

[76] S.N. Sathe, S. Devi, G.S. Srinivasa Rao, K.V. Rao, J. Appl. Polym. Sci. 61 (1996) 97.

[77] A.Y. Coran, R. Patel, H.D. Williame, Rubber Chem. Technol. 58 (1985) 1014.

[78] A. Pozsgay, T. Fráter, L. Százdi, P. Müller, I. Sajó, B. Pukánszky, Eur. Polym. J. 40 (2004) 27.

[79] Y. Li, J. Ma, Y. Wang, B. Liang, J. Appl. Polym. Sci. 98 (2005) 1150.

[80] S.-J. Park, D.-I. Seo, J.-R. Lee, J. Coll. Interf. Sci. 251 (2002) 160.

[81] S.J. Park, J.B. Donnet, J. Coll. Interf. Sci. 206 (1998) 29

[82] J. Ma, J. Xu, J.-H. Ren, Z.-Z. Yu, Y.-W. Mai, Polymer 44 (2003) 4619.

[83] S. Su, C.A. Wilkie, J. Polym. Sci., Part A: Polym. Chem. 41 (2003) 1124.

[84] D.H. Solomon, J.D. Swift, J. Appl. Polym. Sci. 11 (1967) 2567.

[85] Q. Kong, Y. Hu, L. Yang, W. Fan, Z. Chen, Polym. Compos. 27 (2006) 49.

[86] J. Trilica, A. Kalendova, Z. Malac, J. Simonik, in: Proceedings of SPE ANTEC, Dallas, USA, May 6-10 2001.

[87] D.Y. Wang, D. Parlow, Q. Yao, C.A. Wilkie, J. Vinyl Additive Technol. 7 (2001) 203.

[88] H. Qin, Q. Su, S. Zhang, B. Zhao, M. Yang, Polymer 44 (2003) 7533.

[89] M. Zanetti, T. Kashiwagi, L. Falqui, U. Camino, Chem. Mater. 14 (2002) 881.

[90] M. Alexandre, P. Dubois, Mater. Sci. Eng. 28 (2000) 1.

[91] R. Kotsilkova, V. Petkova, Y. Pelovski, J. Therm. Anal. Calorim. 64 (2001) 591.

[92] J. Gilman, T. Kashiwagi, J. Brown, S. Lomakin, E. Giannelis, in: Proceedings of 43rd International SAMPE Symposium, Anaheim, USA, May 31 - June 41998.

[93] J. Lee, T. Takekoshi, E.P. Giannelis, Mater. Res. Soc. Symp. Proc. 457 (1997) 513.

[94] M. Zanetti, G. Camino, R. Thomann, R. Mülhaupt, Polymer 42 (2001) 4501.

[95] Y. Hu, L. Song, in: Proceedings of International Fire Safety Conference (Fire Retardant Chemicals Association), San Francisco, USA, March 11-14 2001.

[96] S. Bourbigot, M. Le Bras, F. Dąbrowski, J.W. Gilman, T. Kashiwagi, Fire Mater. 24 (2000) 201

[97] J. Zhu, C.A. Wilkie, Polym. Int. 49 (2000) 1158.

[98] J.W. Gilman, C.L. Jackson, A.B. Morgan, Chem. Mater. 12 (2000) 1866.

[99] T. Agag, T. Takeichi, Polymer 41 (2000) 7083.

[100] O. Becker, R.J. Varley, G.P. Simon, Eur. Polym. J. 40 (2004) 187.

[101] T. Kashiwagi, R.H. Harris Jr, X. Zhang, R.M. Briber, B.H. Cipriano, S.R. Raghavan, W.H. Awad, J.R. Shields, Polymer 45 (2004) 881.

[102] R.A. Vaia, G. Price, P.N. Ruth, H.T. Nguyen, J. Lichtenhan, Appl. Clay Sci. 15 (1999) 67.

[103] S.W. Benson, P.S. Nogia, Acc. Chem. Res. 12 (1979) 33.

[104] M. Zanetti, P. Bracco, L. Costa, Polym. Degrad. Stab. 85 (2004) 657.

[105] K. Yano, A. Usuki, T. Kurauchi, O. Kamigaito, J. Polym. Sci., Part A: Polym. Chem. 31 (1993) 2493.

[106] Y. Wang, F.-B. Chen, Y.-C. Li, K.-C. Wu, Compos. Part B: Eng. 35 (2004) 111.

[107] J. Zhu, F.M. Uhl, A.B. Morgan, C.A. Wilkie, Chem. Mater. 13 (2001) 4649.

[108] L. Qiu, W. Chen, B. Qu, Polymer 47 (2006) 922.

[109] J.D. Peterson, S. Vyazovkin, C.A. Wight, Macromol. Chem. Phys. 775 (2001) 202.

[110] J.-H. Chang, S.J. Kim, Y.L. Joo, S. Im, Polymer 45 (2004) 919.

[111] H.A. Stretz, M.W. Wootan, P.E. Cassidy, J.H. Koo, Polym. Adv. Technol. 16 (2005) 239.

[112] D. Lee, S.H. Lee, K. Char, J. Kim, Macromol. Rapid Commun. 21 (2000) 1136.

[113] D. Lee, K. Char, Polym. Degrad. Stab. 75 (2002) 555.

[114] A. Blumstein, J. Polym. Sci., Part AI 3 (1965) 2665. 
[115] K. Chen, M.A. Susner, S. Vyazovkin, Macromol. Rapid Commun. 26 (2005) 690.

[116] S. Vyazovkin, I. Dranca, J. Phys. Chem. B 108 (2004) 11981.

[117] S. Vyazovkin, I. Dranca, X. Fan, R. Advincula, J. Phys. Chem. B 108 (2004) 11672.

[118] B.N. Jang, M. Costache, C.A. Wilkie, Polymer 46 (2005) 10678.

[119] B.N. Jang, C.A. Wilkie, Polymer 46 (2005) 3264.

[120] B.N. Jang, C.A. Wilkie, Polymer 46 (2005) 2933.

[121] B.N. Jang, C.A. Wilkie, Polymer 46 (2005) 9702.

[122] M.C. Costache, D. Wang, M.J. Heidecker, E. Manias, C.A. Wilkie, Polym. Adv.

Technol. in press (2006).

[123] C.H. Davis, L.J. Mathias, J.W. Gilman, D.A. Schiraldi, J.R. Shields, P. Trulove, T.E.

Sutto, H.C. Delong, J. Polym. Sci., Part B: Polym. Phys. 40 (2002) 2661.

[124] A. He, H. Hu, Y. Huang, J.-Y. Dong, C.C. Han, Macromol. Rapid Commun. 25 (2004) 2008.

[125] G. Chigwada, D. Wang, D.D. Jiang, C.A. Wilkie, Polym. Degrad. Stab. 91 (2006) 755.

[126] S. Su, D.D. Jiang, C.A. Wilkie, Polym. Degrad. Stab. 83 (2004) 333.

[127] J. Zhang, D.D. Jiang, C.A. Wilkie, Thermochim. Acta 430 (2005) 107.

[128] X. Zheng, D.D. Jiang, D. Wang, C.A. Wilkie, Polym. Degrad. Stab. 91 (2006) 289.

[129] J. Zhang, D.D. Jiang, C.A. Wilkie, Polym. Degrad. Stab. 91 (2006) 298.

[130] G. Chigwada, D.D. Jiang, C.A. Wilkie, Thermochim. Acta 436 (2005) 113.

[131] S.-H. Kim, S.-H. Park, S.-C. Kim, Polym. Bull. 53 (2005) 285. 


\section{Captions for Table and Figures}

Table 1 Organic compounds used for MMT modification with their thermal stability parameters.

Fig. 1 Decomposition mechanism of OLS (adopted from [17]).

Fig. 2 Chemical structure of rigid rod amines used for MMT modification [22].

Fig. 3 Degradation of the imidazolium quaternary salt according to $\mathrm{S}_{\mathrm{N}} 2$ mechanism [29].

Fig. 4 Degradation of the imidazolium quaternary salt according to $\mathrm{S}_{\mathrm{N}} 1$ mechanism [29].

Fig. 5 Synthesis of an organically-modified montmorillonite (C12PPh-MMT) from $\mathrm{Na}^{+}-$ montmorillonite $\left(\mathrm{Na}^{+}-\mathrm{MMT}\right)$ and dodecyltriphenylphosphonium chloride $(\mathrm{C} 12 \mathrm{PPh}-$ C12) [37].

Fig. 6 Formation of epoxy-MMT nanocomposites mediated by ammonium OapPOSS (DGEBA - diglycidyl ether of bisphenol A, monomer; DDM - 4,4'diaminodiphenylmethane, curing agent) [39].

Fig. 7. TG curves of HIPS and its COPS and MAPS nanocomposites [41].

Fig. 8 Structures of alkylammonium compounds used for MMT organofilization: a -dimethyl5-ethylhexadecyl hydrogenated tallow ammonium, $\mathrm{b}$ - methyl dihydroxyethyl hydrogenated tallow ammonium [48].

Fig. 9 Effect of OMMT loading on activation energy of epoxy nanocomposite calculated by Horowitz-Metzger method [49].

Fig. 10 Reactions of MT2EtOH involved during blending in air atmosphere [69].

Fig. 11 Thermal degradation mechanism of PE and EVA in air [104]. 


\begin{tabular}{|c|c|c|c|c|c|}
\hline Organoclay code & Type of organomodifier & $\begin{array}{l}\mathrm{T}_{\text {onset }} \\
{\left[{ }^{\circ} \mathrm{C}\right]}\end{array}$ & $\begin{array}{l}\mathrm{T}_{\max } \\
{\left[{ }^{\circ} \mathrm{C}\right]}\end{array}$ & $\begin{array}{c}\text { Char } \\
{[\%]}\end{array}$ & Ref. \\
\hline DMDODA-MMT & Dimethyldioctadecylammonium chloride & - & $\begin{array}{l}304^{\mathrm{N}} \\
285^{\mathrm{A}}\end{array}$ & - & [123] \\
\hline OMMT & Dimethyldioctadecylammonium bromide & $280^{x}$ & 308 & - & {$[30]$} \\
\hline AMMT & Alkylammonium salt & $281^{\mathrm{y}}$ & 273 & 70.3 & {$[124]$} \\
\hline \multirow[t]{2}{*}{ OMMT } & 1,2-dimethyl-3-hexadecylimidazolium & $343^{x}$ & 406 & - & {$[30]$} \\
\hline & $\mathrm{R}=$ hexadecyl & & & & \\
\hline IMMT & Monoalkylimidazolium salt & $410^{\mathrm{y}}$ & 422 & 78.3 & [124] \\
\hline BPNC16 clay & Phenylacetophenone dimethylhexadecyl ammonium salt & $349^{\mathrm{y}}$ & - & 71 & [125] \\
\hline
\end{tabular}

COPS clay

Ammonium salt of oligomeric copolymer of styrene and vinylbenzyl chloride

$\begin{array}{lll}367 & 427^{z} & 27\end{array}$<smiles>CCC(CC)c1ccccc1</smiles>

MAPS clay

Lauryl clay

PMMA 12 clay

Triclay II

5 AC clay

Ammonium salt of oligomeric copolymer of methyl methacrylate and vinylbenzyl chloride

Ammonium salt of oligomeric copolymer from lauryl acrylate and vinylbenzyl chloride

Salt of methyl methacrylate oligomer<smiles>CC[N+](C)(CC)CCOC(=O)C(C)(CC(C)(C)C)C(C)(C)C(C)(C)CC(C)(C)C(=O)OCC(C)(C)C</smiles>

Ammonium salt of the terpolymer from vinylbenzyl chloride, styrene and lauryl acrylate

Carbazole-based salt

$$
\begin{array}{ccc}
350^{\mathrm{y}} & 418^{\mathrm{z}} & 37.5 \\
325^{\mathrm{y}} & - & 72
\end{array}
$$<smiles>CN(C(C)(C)CCC(C)(C)C)C(C)(C)CCC(C)(C)n1c2ccccc2c2ccccc21</smiles>

Clay dispersed TEO Trimellitate ester oligomer prepared by esterification of 1,2,4-benzenetricarboxylic anhydride (trimellitic anhydride) with ethylene glycol<smiles>O=C(O)c1ccc(C(=O)OCCOC(=O)c2ccc(C(=O)O)c(C(=O)OCCOC(=O)c3ccc(C(=O)O)c(C(=O)O)c3)c2)c(C(=O)O)c1</smiles>

a- $\mathrm{T}_{\max }$ of $1^{\text {st }}$ stage of mass loss; $\mathrm{b}-\mathrm{T}_{\max }$ of $2^{\text {nd }}$ stage of mass loss; $\mathrm{A}$ - measurement in air atmosphere; $\mathrm{N}$ - measurement in nitrogen atmosphere, $\mathrm{x}$ - at degree of conversion $0.05 ; \mathrm{y}$ - at degree of conversion $0.1 ; \mathrm{z}$ - at degree of conversion 0.5

\section{Table 1}




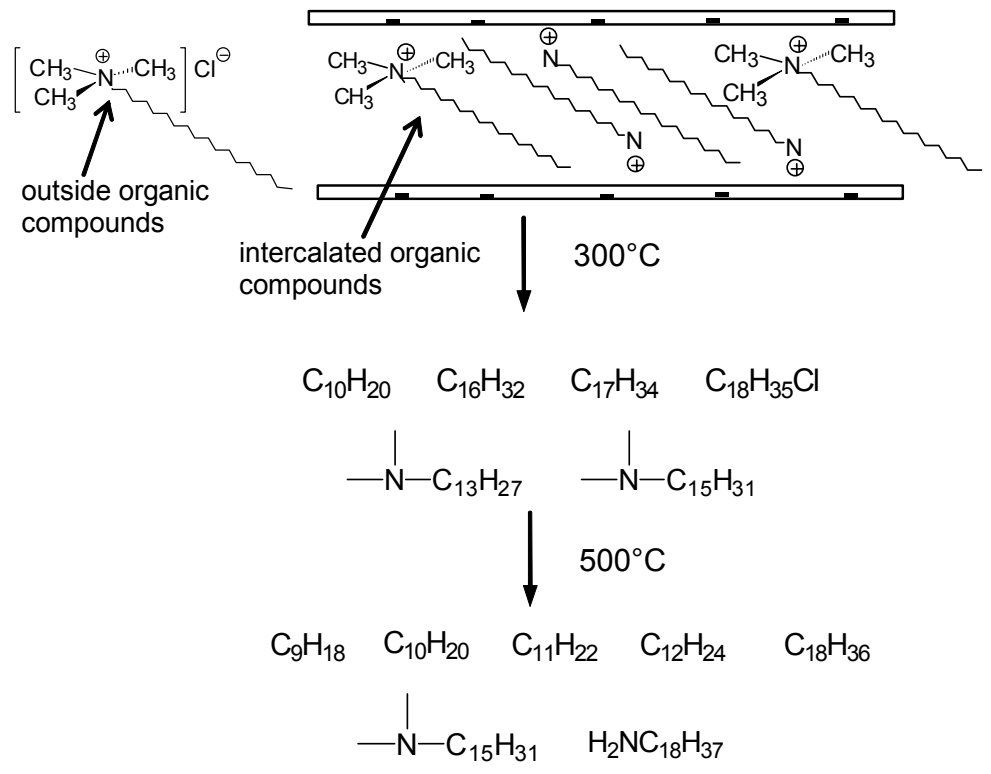

Fig. 1 

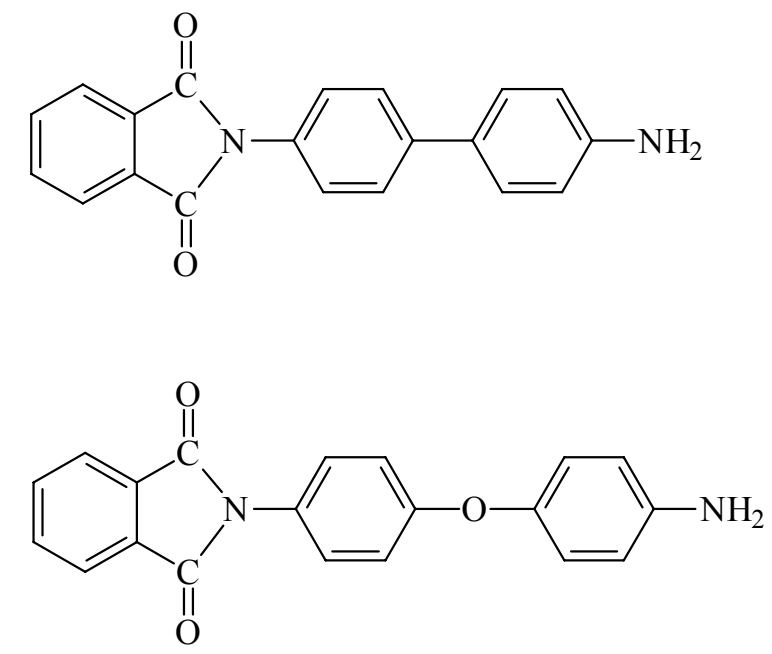

Fig. 2 


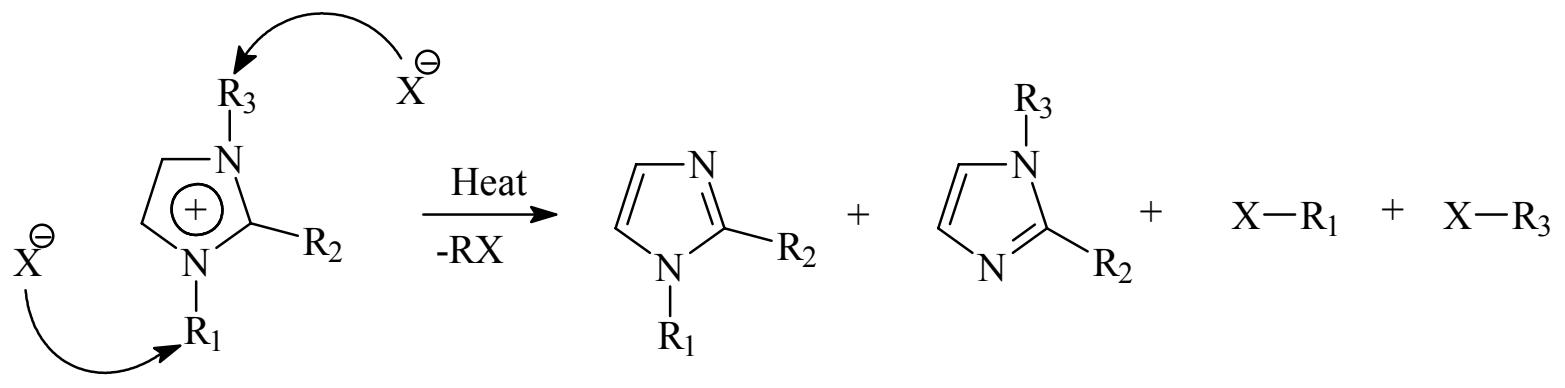

Fig. 3 


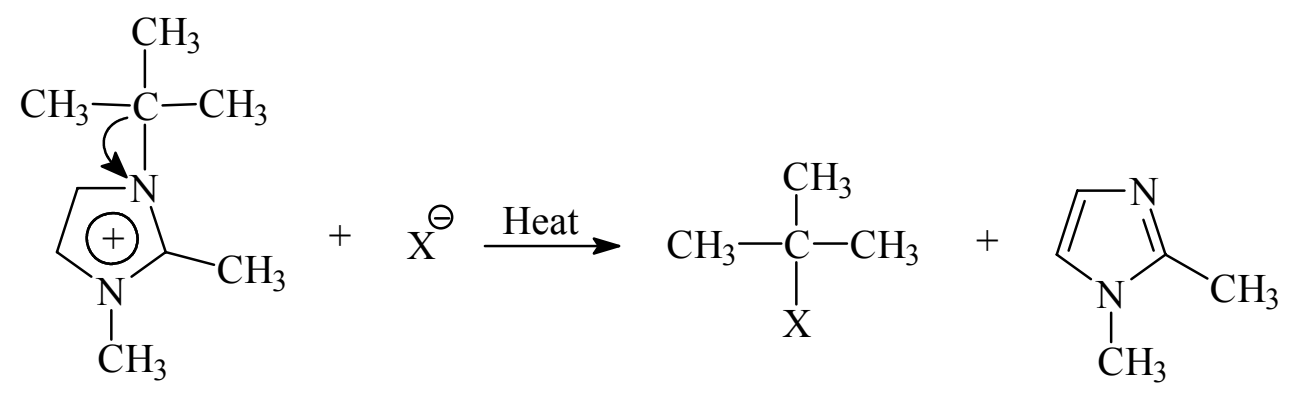

Fig. 4 

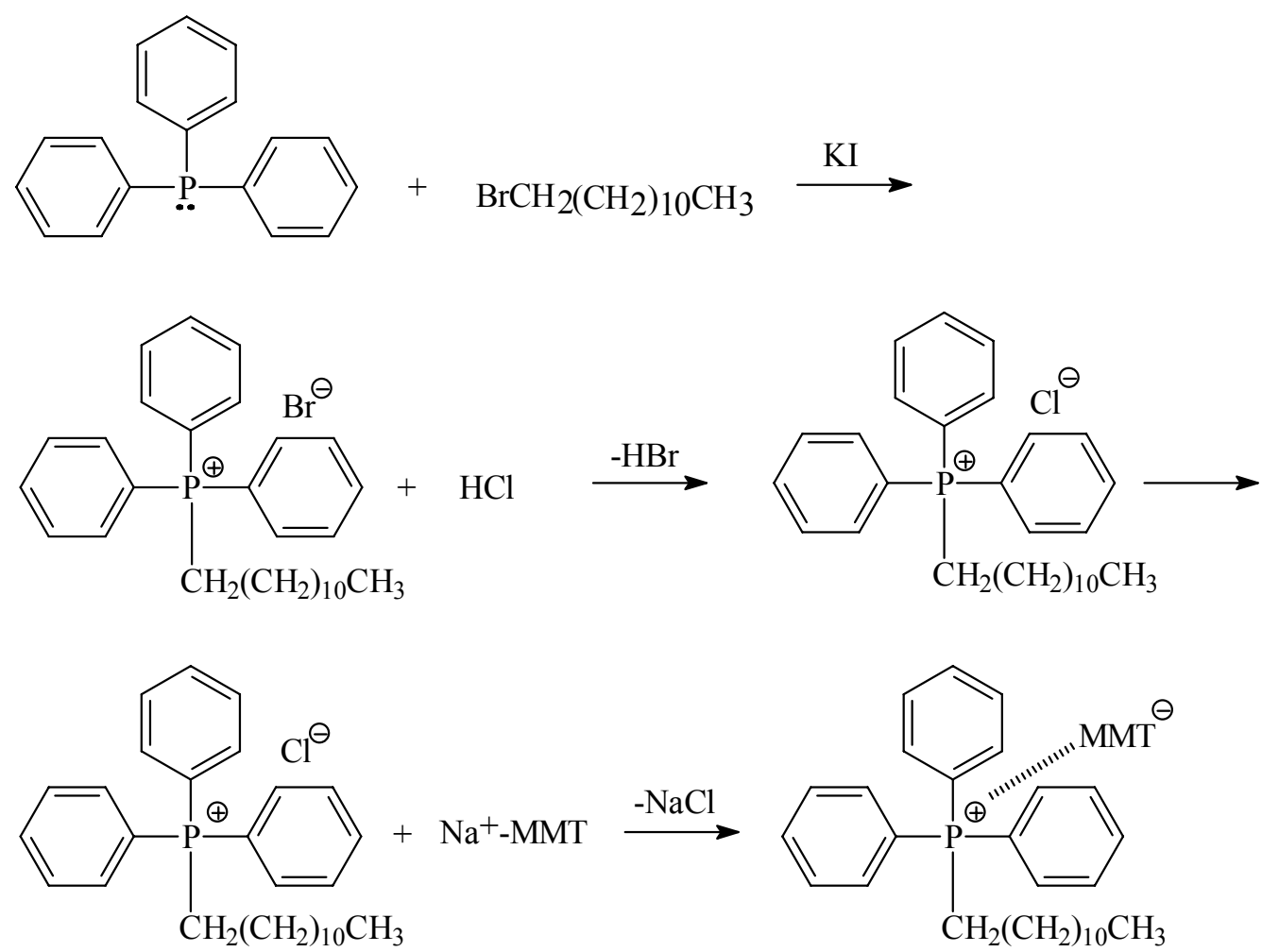

Fig. 5 

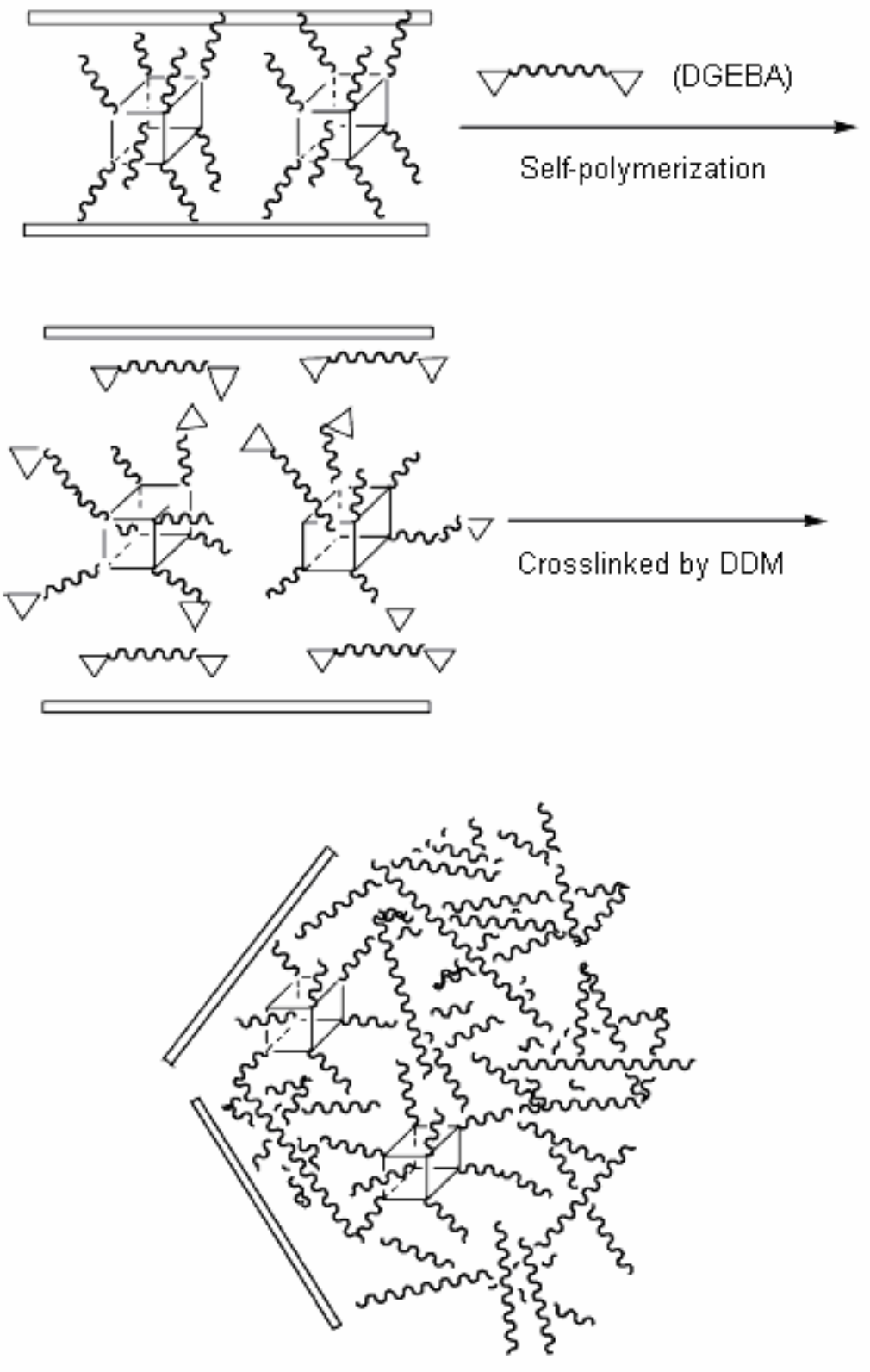

Fig. 6 


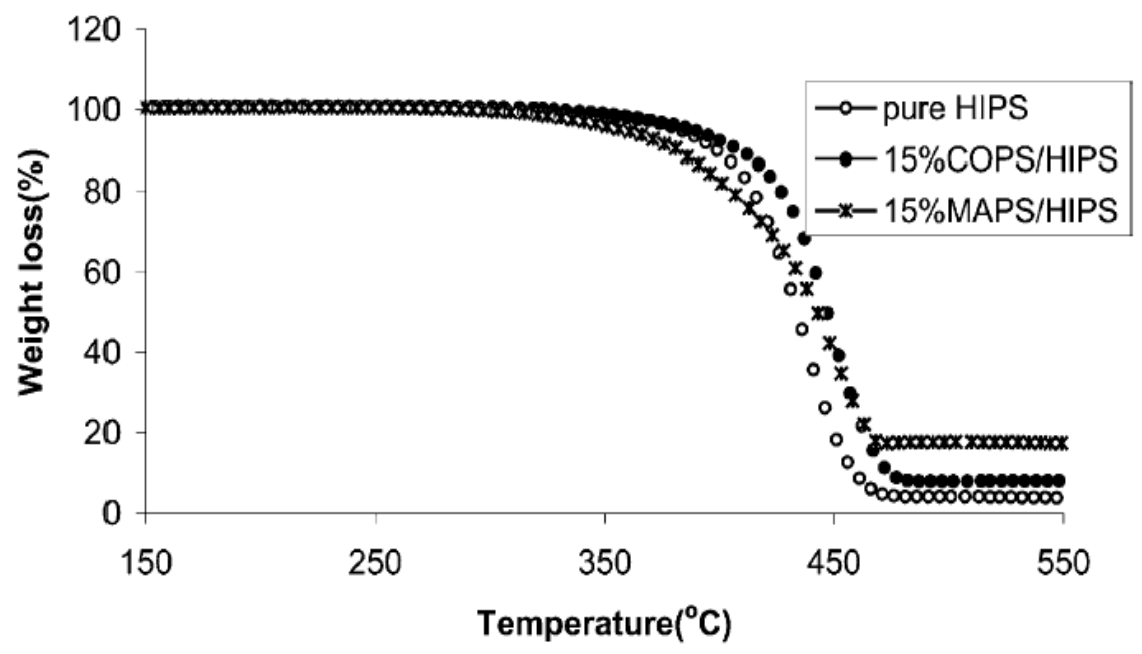

Fig. 7. 


$$
\mathrm{CH}_{\mathrm{CH}_{3}}{ }_{\mathrm{R}}^{\mathrm{C}}-\mathrm{CH}_{2} \mathrm{CH}_{2} \mathrm{OH}
$$

Fig. 8 


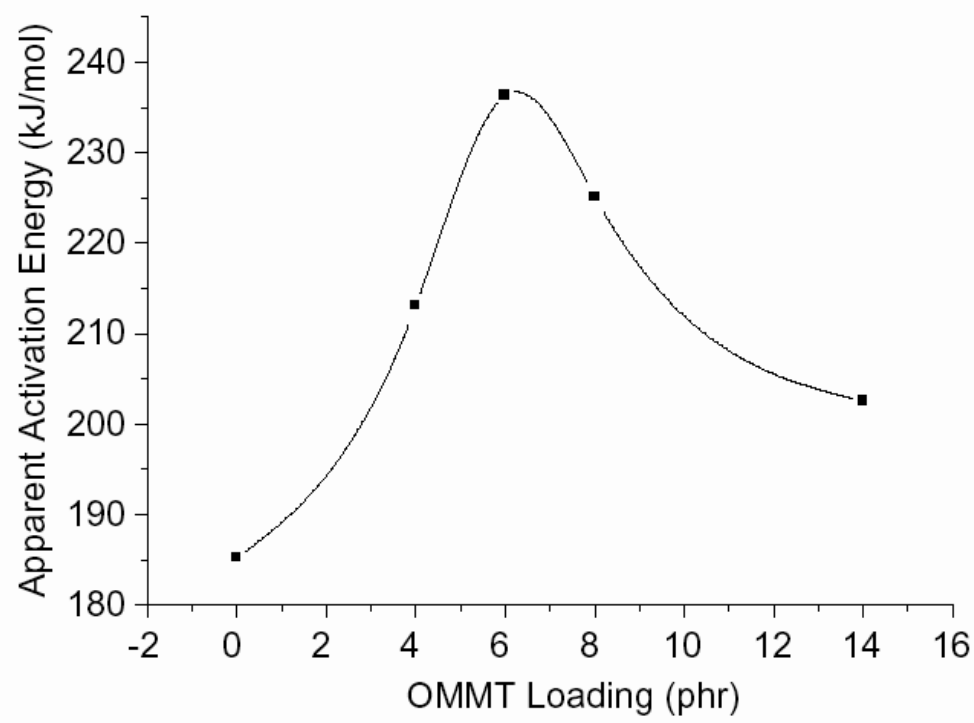

Fig. 9 


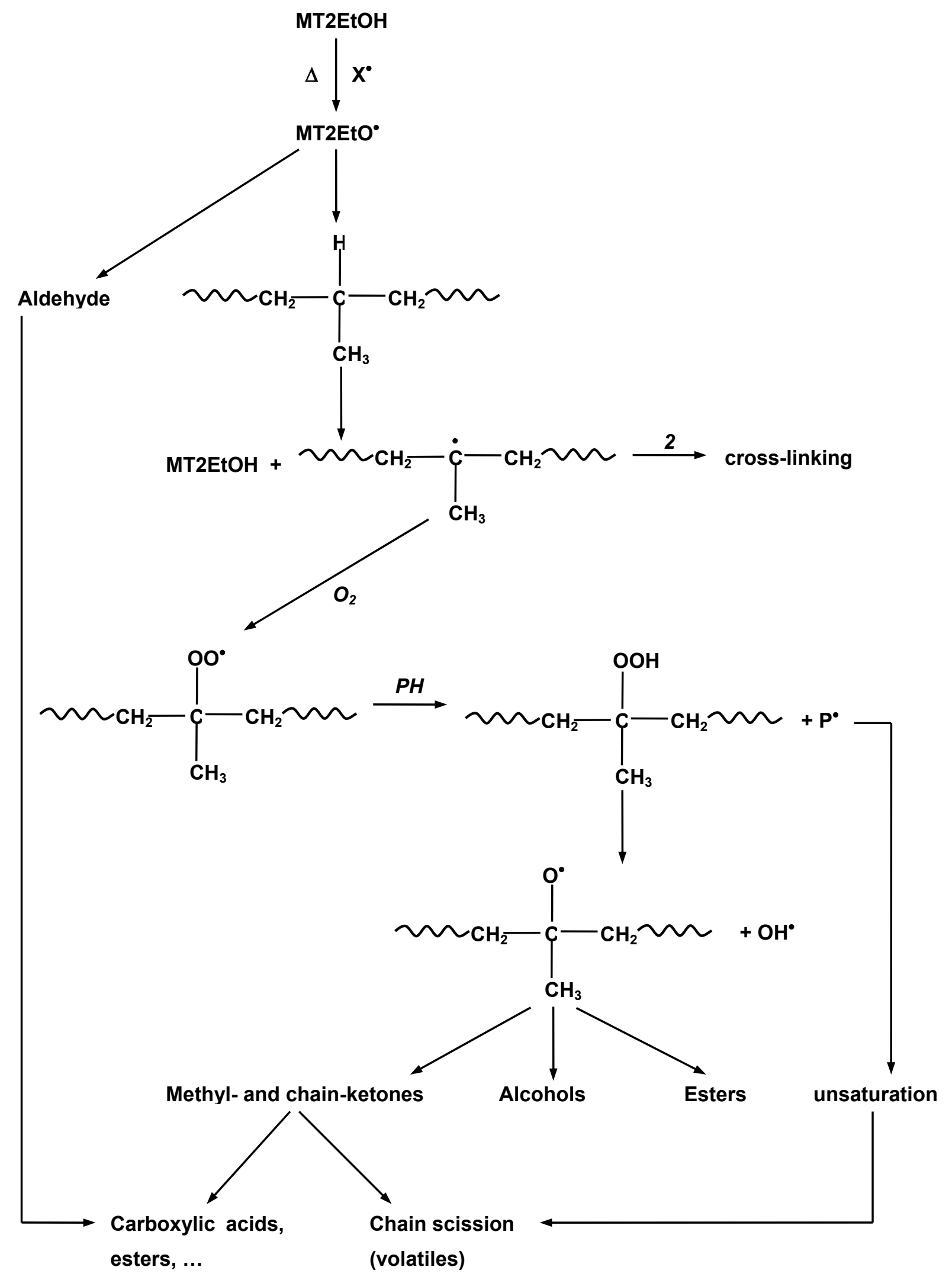

Fig. 10 


\section{EVA}
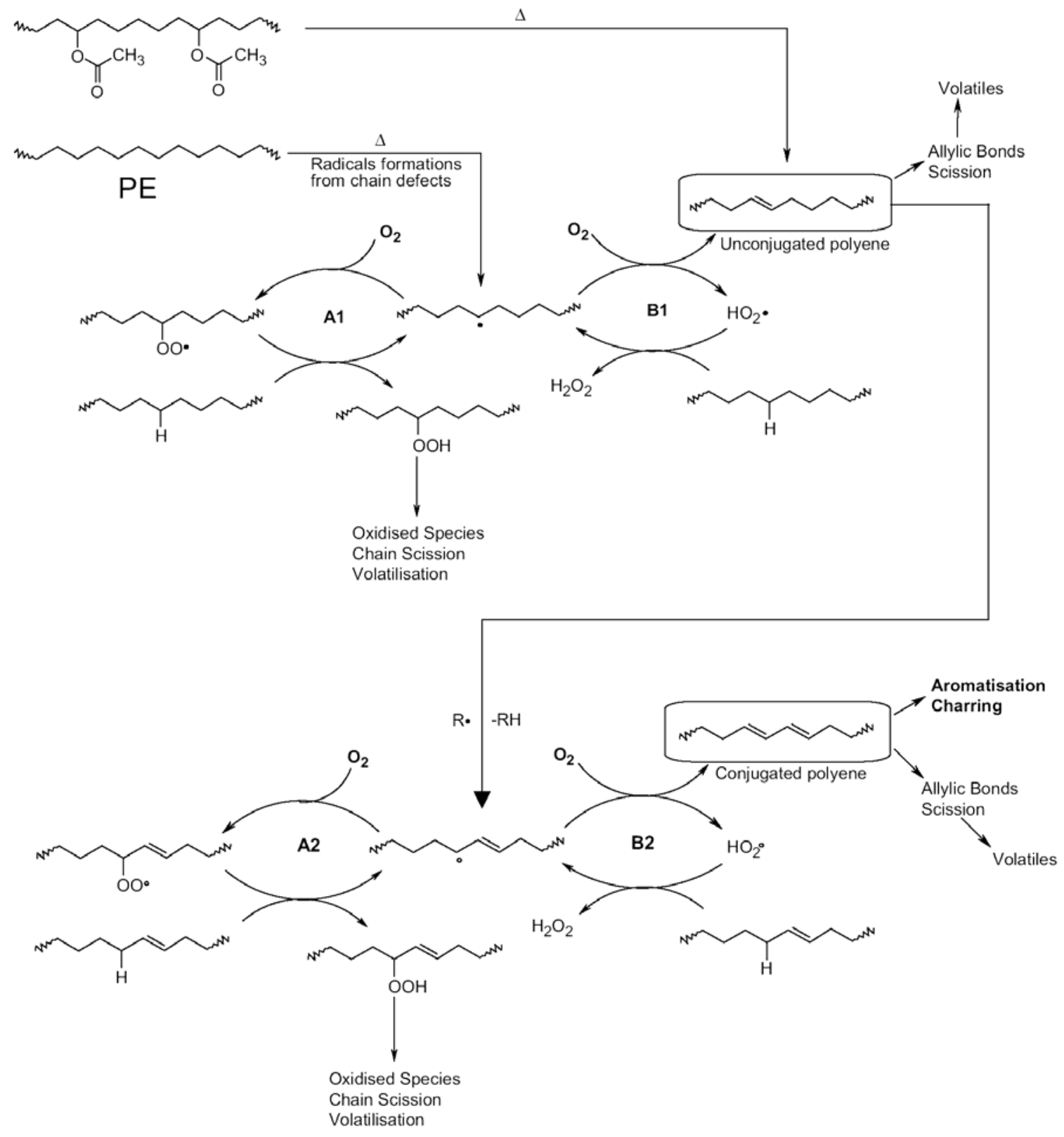

Fig. 11 